\title{
The Structure and Function of Serum Opacity Factor: A Unique Streptococcal Virulence Determinant That Targets High-Density Lipoproteins
}

\author{
Harry S. Courtney ${ }^{1}$ and Henry J. Pownall ${ }^{2}$ \\ ${ }^{1}$ Veterans Affairs Medical Center and Department of Medicine, University of Tennessee Health Science Center, \\ 1030 Jefferson Avenue, Memphis, TN 38104, USA \\ ${ }^{2}$ Department of Medicine, Baylor College of Medicine, Houston, TX 77030, USA
}

Correspondence should be addressed to Harry S. Courtney, hcourtney@uthsc.edu

Received 9 April 2010; Accepted 26 May 2010

Academic Editor: Mari A. Smits

Copyright (C) 2010 H. S. Courtney and H. J. Pownall. This is an open access article distributed under the Creative Commons Attribution License, which permits unrestricted use, distribution, and reproduction in any medium, provided the original work is properly cited.

\begin{abstract}
Serum opacity factor (SOF) is a virulence determinant expressed by a variety of streptococcal and staphylococcal species including both human and animal pathogens. SOF derives its name from its ability to opacify serum where it targets and disrupts the structure of high-density lipoproteins resulting in formation of large lipid vesicles that cause the serum to become cloudy. SOF is a multifunctional protein and in addition to its opacification activity, it binds to a number of host proteins that mediate adhesion of streptococci to host cells, and it plays a role in resistance to phagocytosis in human blood. This article will provide an overview of the structure and function of SOF, its role in the pathogenesis of streptococcal infections, its vaccine potential, its prevalence and distribution in bacteria, and the molecular mechanism whereby SOF opacifies serum and how an understanding of this mechanism may lead to therapies for reducing high-cholesterol concentrations in blood, a major risk factor for cardiovascular disease.
\end{abstract}

\section{Introduction}

Serum opacity factor (SOF) was first discovered in 1938 by the Australians Ward and Rudd [1] as a substance produced by group A streptococci that caused serum to become cloudy (Figure 1), hence its name. SOF was found to act on a lipoprotein fraction of serum $[2,3]$ and various enzymatic activities were proposed to account for the opacity reaction of SOF including those as a cholesterol esterase [4] and apolipoproteinase or aspartic protease [5]. Subsequently, SOF was found not to be a hydrolase but rather induced opacification of serum by binding to highdensity lipoproteins (HDLs), displacing apolipoprotein A-I (apo A-I) and disrupting the structure of HDL resulting in the formation of large, lipid particles that cause serum to become opaque $[6,7]$.

SOF is expressed by a variety of streptococci and staphylococci including both human and animal pathogens. SOF is expressed by approximately $50 \%$ of the invasive isolates of the group A streptococcus, Streptococcus pyogenes, an important human pathogen that colonizes the human skin and the oral cavity where it may stimulate mild to severe local inflammatory responses resulting in pharyngitis in the throat and impetigo in the skin [8]. In susceptible hosts, these infections can lead to life-threatening complications such as sepsis, necrotizing fasciitis, and toxic shock, or to debilitating sequelae such as rheumatic fever and glomerulonephritis [8]. The adhesion to and subsequent colonization of the host by $S$. pyogenes have been attributed to a number of surface exposed molecules including SOF [9]. Furthermore, SOF has been found to contribute to the pathogenesis of streptococcal infections in animal models [10-12] and to evoke protective immune responses in humans and animals [13] indicating its potential as a virulence determinant and vaccine candidate.

SOF is a unique protein exhibiting multiple functions including not only its ability to opacify serum but also an ability to bind to a variety of host proteins such as fibronectin, fibrinogen, and fibulin-1which are involved in 


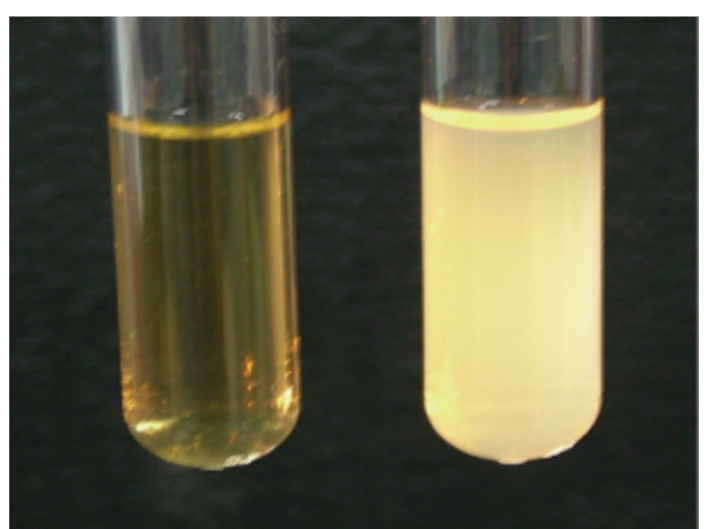

Figure 1: Opacification of human serum by SOF. Human serum was incubated overnight with either buffer control (left) or with $1 \mu \mathrm{g} / \mathrm{ml}$ of recombinant SOF (right).

bacterial adhesion. This paper will provide an overview of the methods of assaying for SOF activity, the structure and function of SOF, its prevalence and distribution in bacteria, its role in contributing to the pathogenesis of streptococcal infections, its vaccine potential, and how investigations into the mechanisms whereby SOF opacifies serum may lead to therapies to help control atherosclerosis.

\section{Assays for Detecting and Measuring the Opacity Reaction of SOF}

2.1. Soluble Forms of SOF. Whether a particular strain of bacteria expresses SOF can be determined by several techniques. Activity of SOF in growth supernatants of bacteria can be tested by centrifugation of overnight cultures of the organisms and addition of $100 \mu \mathrm{L}$ of the supernatant to $1 \mathrm{~mL}$ of horse serum containing sodium azide to inhibit bacterial growth. After incubating overnight at $37^{\circ} \mathrm{C}$, the opaqueness of serum is very visible (illustrated in Figure 1) and this can be quantified by measuring the absorbance at $405 \mathrm{~nm}$.

SOF activity that is noncovalently associated with the bacterial surface can be detected by extracting a streptococcal pellet from $10 \mathrm{ml}$ of culture with $0.5 \mathrm{ml}$ of $1 \%$ SDS and adding $100 \mu \mathrm{l}$ of the extract to $1 \mathrm{ml}$ of horse serum and recording the absorbance at $405 \mathrm{~nm}$ after an overnight incubation at $37^{\circ} \mathrm{C}$. SDS extraction has been shown to be an accurate and sensitive method for the detection of SOF activity [14].

Bacterial extracts can also be examined for opacifying activity by solid agar techniques. One example of this is the application of bacterial extracts containing SOF to agar that has been mixed with $50 \%$ horse serum [15]. Opacifying activity is denoted by opaque areas surrounding the applied sample. Alternatively, extracts containing SOF can be subjected to SDS-PAGE and the SDS-gel is overlaid with agar containing $50 \%$ horse serum $[10,16,17]$. Opacifying activity is detected by the appearance of opaque bands after a period of incubation in a moist environment. This last technique has the advantage over other assays in that active fragments of SOF can be distinguished from inactive fragments without the need for purification.

2.2. Insoluble Forms of SOF. Extraction with SDS will only remove SOF that is loosely associated with the surface or SOF that is still in the membrane and is not covalently attached. In fact, only a minor amount of the total SOF is released by SDS extraction (Courtney et al., unpublished results) as would be expected if most of the SOF on the streptococcal surface were covalently attached via a sortase recognition site. SOF that is covalently linked to the cell wall can be detected by washing and suspending the bacteria from $10 \mathrm{ml}$ of culture in $1 \mathrm{ml}$ of PBS, adding $100 \mu \mathrm{l}$ of this suspension to $1 \mathrm{ml}$ of horse serum containing $0.2 \%$ sodium azide to block bacterial growth and recording the $\mathrm{A}_{405}$ after an overnight incubation. Negative controls would include streptococci that do not express SOF or SOF-negative mutants.

SOF can also be immobilized on surfaces and used in the opacity reaction. In one example of this type of assay, plastic tubes were coated with fibronectin and reacted with SOF, which binds to fibronectin. The tubes were then washed multiple times followed by the addition of horse serum and incubation for several days. SOF remained bound to fibronectin and was still able to opacify serum after 3 days and multiple washes [10]. This suggests that SOF that has bound to fibronectin-coated surfaces in the host may retain its ability to opacify serum and such binding may allow SOF to accumulate in the host during an infection.

2.3. Microtiter Method. For assays in which the amount of reagents is a limiting issue, a microtiter method can be used [15]. For example, serum from human donors may be limited. Purified lipoproteins are somewhat expensive and therefore, techniques that reduce the amounts of these reagents can be cost saving. In a typical assay, $200 \mu \mathrm{l}$ of serum or purified lipoprotein is added to microtiter wells and then various concentrations of SOF are added. The microtiter plate should be incubated in a moist environment at $37^{\circ} \mathrm{C}$ and the absorbance at $405 \mathrm{~nm}$ recorded at timed intervals.

2.4. Substrates for the Opacity Reaction of SOF. Horse serum is commonly used to measure the opacity reaction of SOF due to its availability and cost. Variations in the final absorbance values have been noted with different lots of horse serum and other animal sera probably due to variations in the concentration of HDL. Other animal serum may also be used, however, not all animal sera works with all serotypes of SOF. For example, SOF from M types 9, 11, 28, and 49 opacifies horse serum, but SOF from these serotypes does not work well in rabbit serum [18] and there may be other examples where SOF from a particular serotype of $S$. pyogenes does not work well in certain animal sera as this has not been examined in detail.

Human sera can be used as well but care needs to be taken to ensure that no neutralizing antibodies are present in the sera. Antibodies against SOF are found in human sera due to prior infections with SOF-positive streptococci 
and in some instances these antibodies can neutralize the opacity reaction of SOF from a particular serotype. In fact, type-specific antibodies in serum that neutralize SOF have been used to serotype strains of $S$. pyogenes [18-20]. This form of serotyping was particularly useful for those strains that were refractory to $M$ protein serotyping and is based on the findings that the SOF type-specific determinants covary with the type-specific determinants of $\mathrm{M}$ proteins. Thus, identification of the SOF serotype predicted the M serotype with only a few exceptions [21]. This is mostly of historical significance as strains are currently genotyped by sequencing the $5^{\prime}$ terminus of the emm gene (the gene for M protein).

Purified HDL can also be used as a substrate for the opacity reaction of SOF. Other lipoproteins such as very low-density lipoprotein (VLDL) and low-density lipoprotein (LDL) are not opacified by SOF and can serve as negative controls [6].

It is also important to note that serial dilutions of extracts with SOF or bacteria should be used in the above assays, at least initially, as the opacification of serum can be reduced at high concentrations of SOF. Thus, a false negative or a low value may be obtained if only one concentration of extract is tested and that contains high levels of SOF. In most opacity assays SOF appears to be optimal at around $1 \mu \mathrm{g} / \mathrm{ml}$. However, there are many serotypes of $S$. pyogenes in which the SOF has not been tested and there may be some that exhibit a different dose response curve.

\section{Structure and Function of SOF}

3.1. Structure of SOF. The gene for SOF was first cloned and sequenced by Rakonjac et al. [16] and a repeating peptide was identified within this sequence that bound fibronectin. Kreikemeyer et al. [22] cloned and sequenced a gene for a fibronectin-binding protein from $S$. pyogenes that was subsequently found to be virtually identical to sof cloned by Rakonjac et al. [16] A number of sof genes from other serotypes were later cloned and sequenced or available from whole genomes of streptococci (Table 1). Analysis of the predicted amino acid sequences of SOF indicates that the leader sequence and the C-terminal regions containing the fibronectin-binding domain are highly conserved and there are additional stretches of highly conserved sequences interspersed among areas of high variation (Figure 2). There is approximately 40 to $60 \%$ homology between SOF from different serotypes of $S$. pyogenes (Figure 3 ). Interestingly, the secondary structure of SOF from different serotypes of $S$. pyogenes has been remarkably retained even across those areas of high divergence (Figure 4). However, there is less similarity between SOF from $S$. pyogenes and that from $S$. dysgalactiae (31\% to $38 \%$ ) and even less with SOF from S. suis ( 20\%) (Figure 3). Note that SOF from S. suis has been termed OFS (opacity factor of S. suis) [11] but we have retained the term SOF in this review for reasons of consistency.

Some of the diversity of structure of SOF is related to its propensity for gene rearrangement. Wertz et al. [31] identified several modules of sof that are highly conserved
TABLE 1: Accession numbers for sof sequences.

\begin{tabular}{|c|c|c|}
\hline SOF serotype & $\begin{array}{l}\text { Nucleotide sequence } \\
\text { accession numbers }\end{array}$ & References \\
\hline sof 2 & AF019890, CP000260 & {$[10,23]$} \\
\hline sof4 & AY162273, CP000262 & {$[13,23]$} \\
\hline sof 12 & AF387738, CP000259 & {$[23,24]$} \\
\hline sof 13 & AF367016 & {$[17]$} \\
\hline $\operatorname{sof} 22^{\mathrm{a}}$ & UO2290 & {$[16]$} \\
\hline sof 28 & AF082074, CP000056 & {$[10,25]$} \\
\hline sof 49 & AF057697, CP000829 & {$[10,26]$} \\
\hline sof61 & AF138804, AF139752 & $\begin{array}{c}\text { direct } \\
\text { submission }\end{array}$ \\
\hline sof 63 & AF191974 & [27] \\
\hline $\operatorname{sof} 75^{\mathrm{b}}$ & X83303 & {$[22]$} \\
\hline sofVT3.1 & AF367012 & {$[17,28]$} \\
\hline sofVT3.2 & AF367011 & {$[17]$} \\
\hline $\operatorname{sofVT} 21^{\mathrm{c}}$ & AF367014 & {$[17]$} \\
\hline sofVT37.1 & AF367015 & {$[17]$} \\
\hline $\operatorname{sof} 90^{\mathrm{d}}$ & AF367013 & {$[17]$} \\
\hline S. dysgalactiae sof ${ }^{\mathrm{e}}$ & Z22150 & {$[29]$} \\
\hline S. suis sof & $\begin{array}{l}\text { AY819647, AB325706 } \\
\text { AB325707, AB325708 } \\
\text { AB325709, AB325710 }\end{array}$ & {$[11,30]$} \\
\hline
\end{tabular}

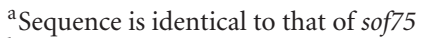

${ }^{\mathrm{b}}$ Was initially termed sfb 1

${ }^{c}$ VT indicates virulence typing, a PCR-based genotyping scheme

${ }^{\mathrm{d}}$ Also termed sofVT2.2

${ }^{\mathrm{e}}$ Also termed fnbA.
}

and are duplicated numerous times within sof and contain inverted repeats. Such duplications and inversions can lead to higher frequencies of recombinational events and variations in protein sequences that may aid the streptococcus in escaping immune surveillance.

There are several protein motifs that are conserved in SOF (Figure 2). A leader sequence that targets proteins for transport across the membrane is highly conserved among $\mathrm{SOF}$ from various serotypes of $S$. pyogenes. There are variants of the leader sequence in SOF from S. suis that in some cases result in expression of a truncated peptide [30]. There is an LPXXG anchoring motif that serves as a site for the sortase enzyme that cleaves SOF and covalently attaches it to the cell wall [32].

Another conserved domain in SOF is the von Willebrand Factor A (vWFA) domain, so named because it was originally found in the blood coagulation protein von Willebrand factor. The vWFA domain is vital for proper control of hemostasis and thrombosis and a wide spectrum of other cellular activities, which are mediated primarily by ligand/receptor interactions [33]. A metal ion-dependent adhesion site (MIDAS) is found within the vWFA domain of SOF, as it is in many of the vWFA domains in eukaryotic proteins. Based on functions of eukaryotic vWFA domains, this domain in SOF may mediate interactions with host cell integrins and/or other cellular receptors. Furthermore, 


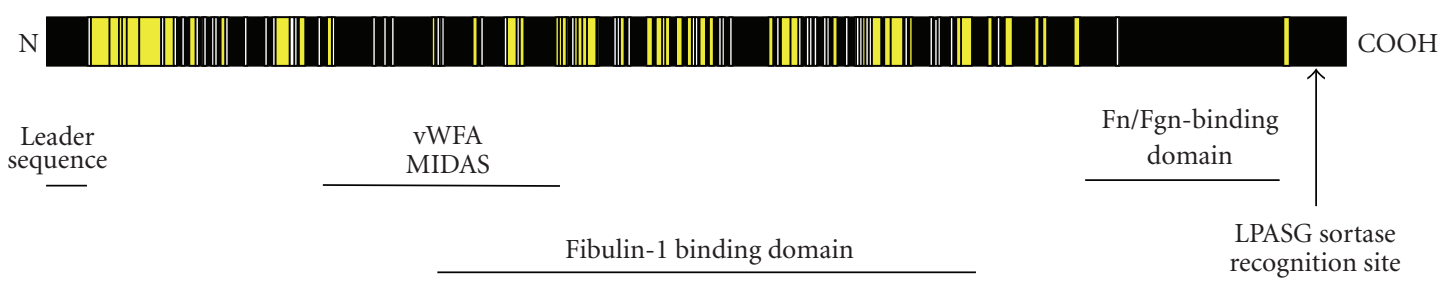

Opacification domain

FIGURE 2: A schematic indicating the location of functional domains within SOF. The yellow segments in the top bar indicate regions of SOF that are highly variable (vary in $\geq 60 \%$ of serotypes), black segments indicate highly conserved regions of SOF (conserved in $\geq 60 \%$ of serotypes. Only SOFs from $S$. pyogenes were used to generate this illustration. There are variations in the size of SOF from different serotypes but most are composed of $\sim 1050$ amino acids including the leader sequence. The black lines signify the general location and size of the indicated domains. Abbreviations: vWFA: von Willebrand Factor A domain, MIDAS: metal ion-dependent adhesion site, Fn/Fgn: fibronectin/fibrinogen.

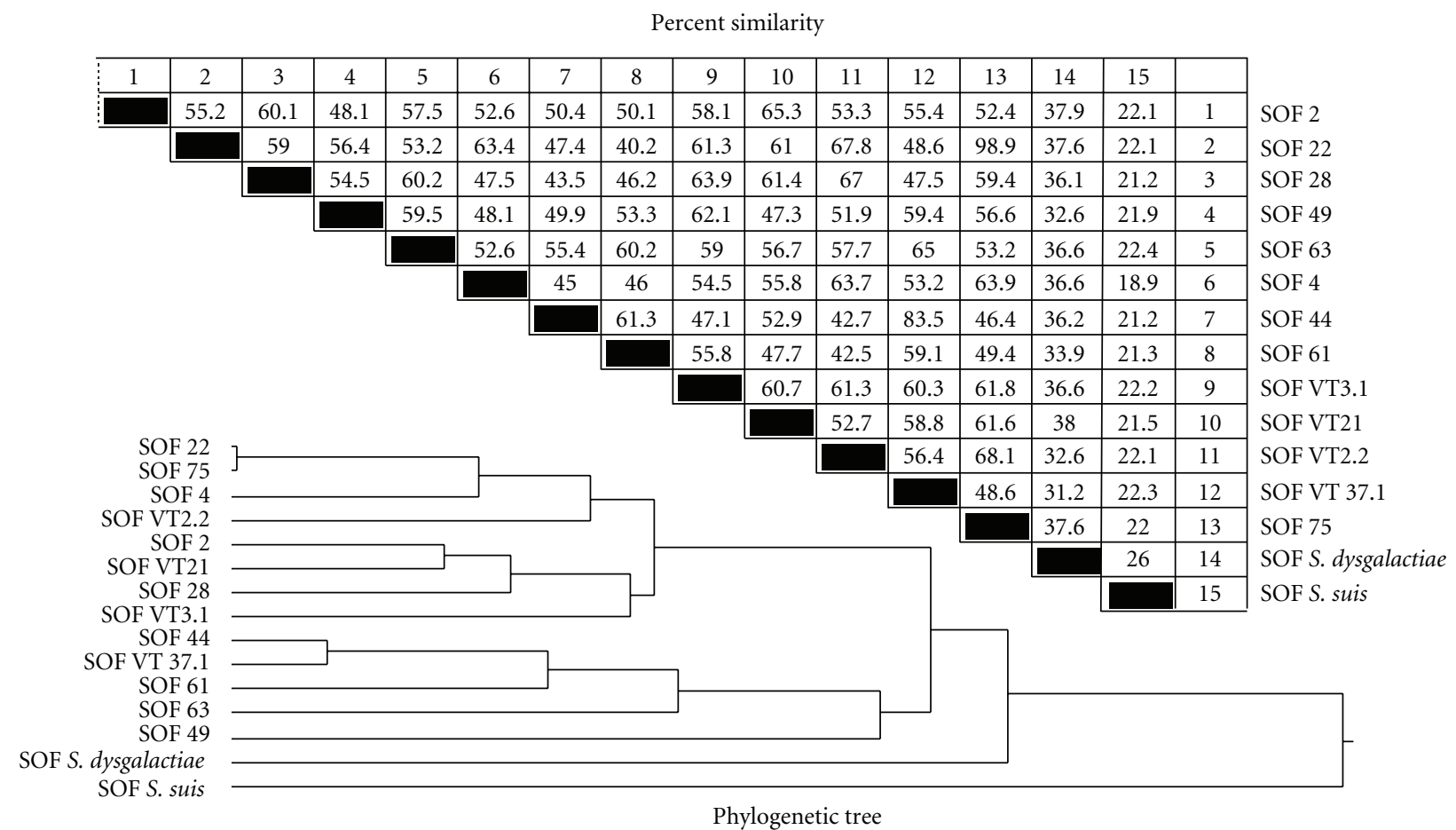

FIGURE 3: A comparison of the similarity between SOF from various serotypes of S. pyogenes and other streptococci (top). The bottom part of the figure illustrates the phylogenetic tree of SOF from different streptococci.

because a MIDAS motif is found in all SOFs, metal ions are likely to be involved in this binding activity. While SOF is known to mediate streptococcal adhesion/invasion (see Section 3.2.2), there has been no investigation into the role of the vWFA domain of SOF in the attachment and invasion of host cells by streptococci and its function remains to be resolved.

A repeating peptide is found in the C-terminus of all SOF from S. pyogenes and S. dysgalactiae that have been examined to date. This repeating peptide domain binds fibronectin and it shares homology with a number of other fibronectin-binding repeat peptides of other bacterial proteins [9]. However, the C-repeat peptide of SOF from $S$. suis has little similarity with that of S. pyogenes and does not bind fibronectin and its function remains to be determined [11].

\subsection{Functions of SOF}

3.2.1. Opacification Reaction of SOF. That high-density lipoprotein (HDL) is the target of SOF in the opacity reaction is supported by the findings that SOF neither opacified human serum depleted of HDL nor serum from apo- $\mathrm{AI}^{-/-}$ mice, which are deficient in HDL [6]. Furthermore, SOF readily opacified purified HDL but did not opacify LDL (lowdensity lipoprotein) or VLDL (very low-density lipoprotein). 


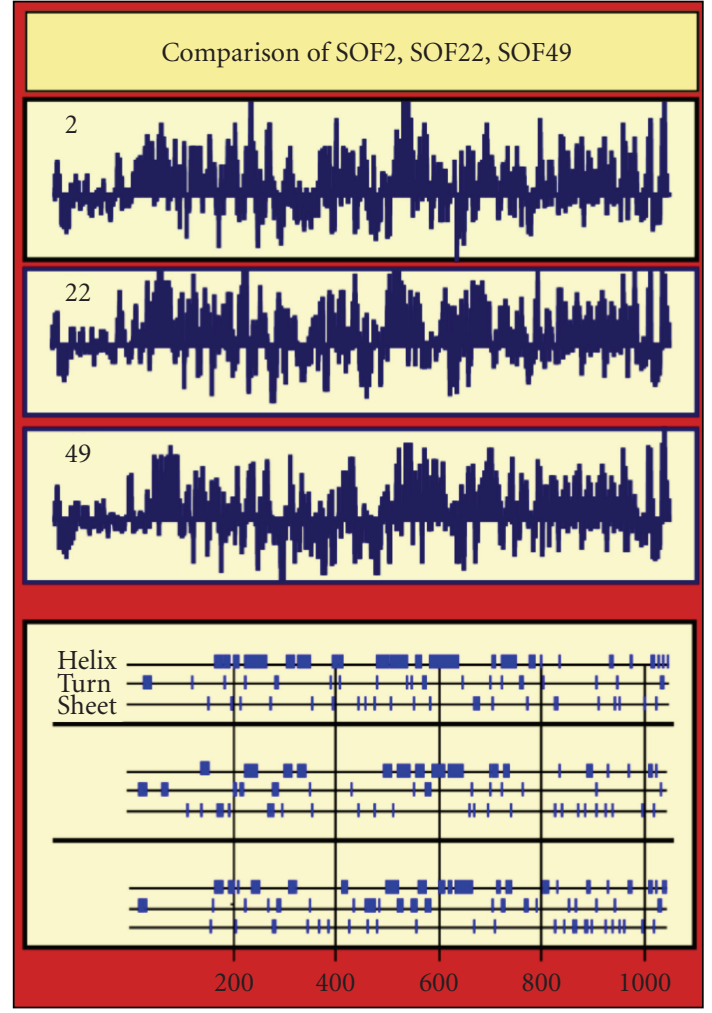

FIgURe 4: The predicted secondary structure of SOF is highly conserved among SOF from different serotypes. Only three serotypes were selected for comparison in order to have a manageable figure. The top figure indicates the degree of hydrophobicity/hydrophilicity and the bottom figure indicates location of helixes, turns, and Bsheets. The numbering of the amino acids is indicated.

It has been previously suggested that SOF may be an enzyme with esterase or lipase activity or that it is an aspartic protease that degrades apo A-I $[4,5,34]$. That SOF is not a hydrolytic enzyme is indicated by the following observations: (1) Purified, recombinant SOF did not degrade any of the apolipoproteins of HDL; (2) SOF did not exhibit any lipolytic activity; (3) A battery of lipase and protease inhibitors including an aspartic protease inhibitor had no effect on the opacity reaction of SOF. Although one inhibitor, dichloroisocoumarin, did inhibit the opacity reaction, this was due to nonspecific modification of amino acids leading to loss of binding of SOF to HDL and thereby, loss of opacifying activity [6].

So, if SOF is not a hydrolytic enzyme, then how does it opacify serum? Clues to a possible mechanism can be gathered from studies on HDL and its disruption by chaotropic agents. HDL contains a central core composed primarily of cholesterol esters and triglycerides surrounded by a layer of cholesterol, phospholipids, and apolipoproteins (mainly apo A-I and A-II). These components of HDL are stabilized by kinetic factors and destabilization can be induced by detergent, thermal, or chaotropic perturbations that lead to dissolution of HDL and the concomitant release of free apo A-I [35-37]. The kinetic stability of HDL is

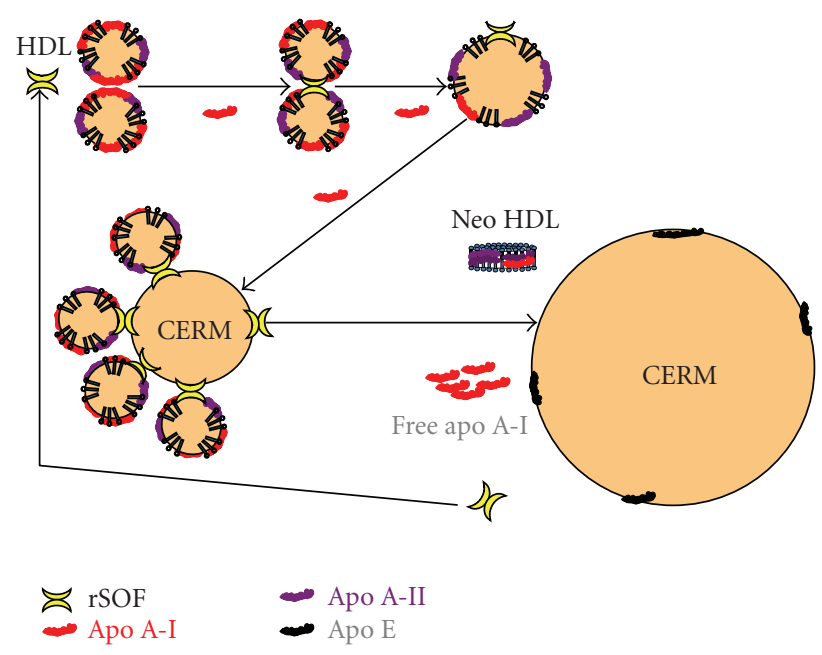

FIGURE 5: Model of the opacification reaction of SOF with high-density lipoproteins (HDLs). SOF initiates the opacification reaction by binding to HDL. SOF is a heterodivalent fusogen that crosslinks two or more HDL particles and simultaneously induces the release of free apo A-I and promotes the fusion of the resultant particles culminating in the formation of a cholesterol-ester rich microemulsion (CERM) and neo-HDL. Neo-HDL is deficient in free cholesterol/cholesterol esters and rich in phospholipids and apo A-II. Some HDL particles also contain apo E, which is preferentially retained in CERM. Structures are not drawn to scale. CERM particles range from 100 to $500 \mathrm{~nm}$ in size whereas HDL particles are $\sim 8.5 \mathrm{~nm}$ [38]. Current data indicates one CERM particle contains cholesterol-esters from $\sim 400,000 \mathrm{HDL}$ particles. It is these CERM particles that cause serum to become opaque due to their large size and insolubility in aqueous solutions.

a measure of the rate at which the particle dissolves and determines the half life of the particle in solution. Thus, agents that interfere with the kinetic stability of HDL will lead to rapid dissolution of the structure of HDL.

SOF binds to HDL with high affinity and according to chemical kinetics, SOF is a heterodivalent fusogen that induces the release of free apo-I, the formation of a neoHDL particle that contains apo A-I and A-II and is enriched in phospholipids, and the formation of cholesterol esterrich microemulsion (CERM) that fuses to from very large CERM particles (Figure 5). An electron micrograph of these particles is shown in Figure 6 and serves to illustrate the fusion of particles and the formation of large, lipid particles.

It is the formation of these large CERM particles that causes opacification of serum due to their large size and insolubility in aqueous media. SOF is potent and catalytic with a $10 \mathrm{nM}$ concentration of SOF totally opacifying $8 \mu \mathrm{M}$ HDL (an 800 fold excess of HDL) in 1 hour at $37^{\circ} \mathrm{C}$. SOF induces the transfer of nearly all of the neutral lipids of $100,000 \mathrm{HDL}$ particles $(\sim 8.5 \mathrm{~nm}$ diameter $)$ to a single CERM particle (100-500 nM diameter) [7, 38]. A key component of HDL that is required for the opacity reaction is a labile form of apo A-I and the rate-limiting step in the opacity reaction is the release of free apo A-I. [39]. Other apolipoproteins 


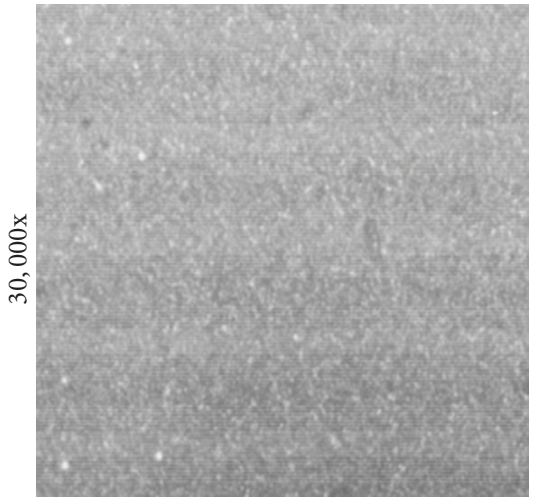

(a)

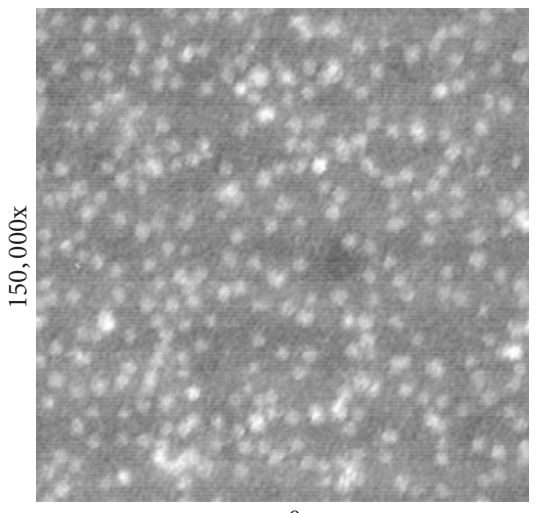

0

$\operatorname{SOF}(\mu / \mathrm{mL})$

(c)

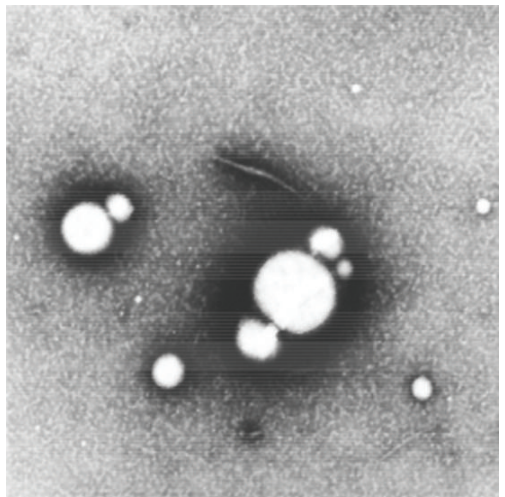

(b)

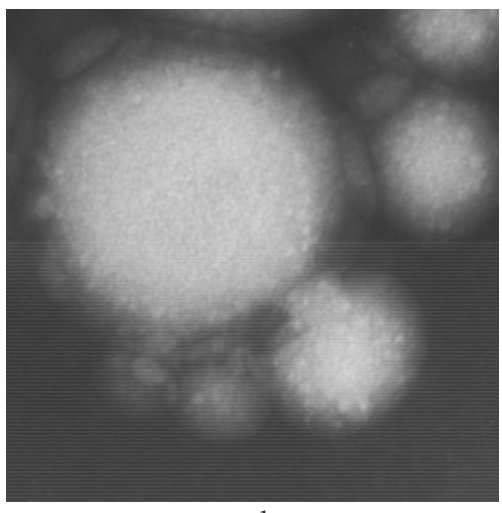

1

$\operatorname{SOF}(\mu / \mathrm{mL})$

(d)

FIGURE 6: Electron micrographs of HDL treated with SOF. Indicated concentrations of rSOF were incubated with human HDL overnight at $37^{\circ} \mathrm{C}$, stained with $2 \%$ phosphotungstic acid, and electron micrographs taken at the indicated magnification.

will not substitute for apo A-I. Murine HDL is opacified at faster rate than human HDL and this is most likely due to the higher hydropathy of human apo A-I as compared to that of murine apo A-I, which would allow a faster displacement of murine apo A-I by SOF [39].

3.2.2. Role of SOF in Streptococcal Adhesion and Invasion. The two major portals for group A streptococcal infections are the tissues of the skin and oral cavity. It has long been recognized that there are serotypes of $S$. pyogenes that primarily cause skin infections, serotypes that primarily infect oral sites, and serotypes that infect tissues of both the oral mucosa and skin. SOF is expressed by those serotypes that infect both the oral epithelium and skin tissues. Thus, SOF may be involved in the colonization of the host by certain serotypes of $S$. pyogenes.

One of the first indications that SOF may actually be involved in streptococcal adhesion was the finding that SOF binds to fibronectin $[10,16,22,27,28]$, an important component of the extracellular matrix and host surfaces that has been found to mediate adhesion of a wide variety of bacteria (Figure 7). Antiserum against SOF blocked adhesion of $S$. pyogenes to HEp-2 cells suggesting that SOF is involved in streptococcal adhesion to host cells [40]. SOF was found to react with the $\mathrm{N}$-terminal, $30 \mathrm{kDa}$ fragment of fibronectin, the same region of fibronectin that binds to $S$. pyogenes [40]. Coating latex beads with SOF promoted adhesion of these beads to HEp-2 tissue culture cells and also enhanced phagocytosis of these beads [40]. Gillen et al. [41] demonstrated that both the C-terminal fibronectin-binding domain of SOF (FBD) and SOF in which the fibronectinbinding domain was deleted (SOF $\triangle \mathrm{Fn}$ ) are involved in adhesion and invasion of host cells, as both of these forms mediated adhesion/invasion but not as efficiently as full length SOF. Furthermore, SOF $\Delta$ Fn was more effective than the C-terminal FBD in promoting adhesion of latex beads to host cells, but the FBD fragment was more effective in promoting invasion of host cells by latex beads than SOF $\Delta F n$. Interestingly, mutations that attenuated the opacity reaction of SOF had no effect on adhesion indicating that these functions are separate and distinct [41].

Another fibronectin-binding protein of $S$. pyogenes is Sfbx and its gene is found immediately downstream of sof (Figure 8) and is cotranscribed with sof as a bicistronic message [24]. Timmer et al. [12] engineered nonpolar mutants in these two genes in $\mathrm{M}$ type 49 S. pyogenes in order to evaluate their respective roles in host cell invasion. Inactivation of sof in $S$. pyogenes caused a $50 \%$ reduction 


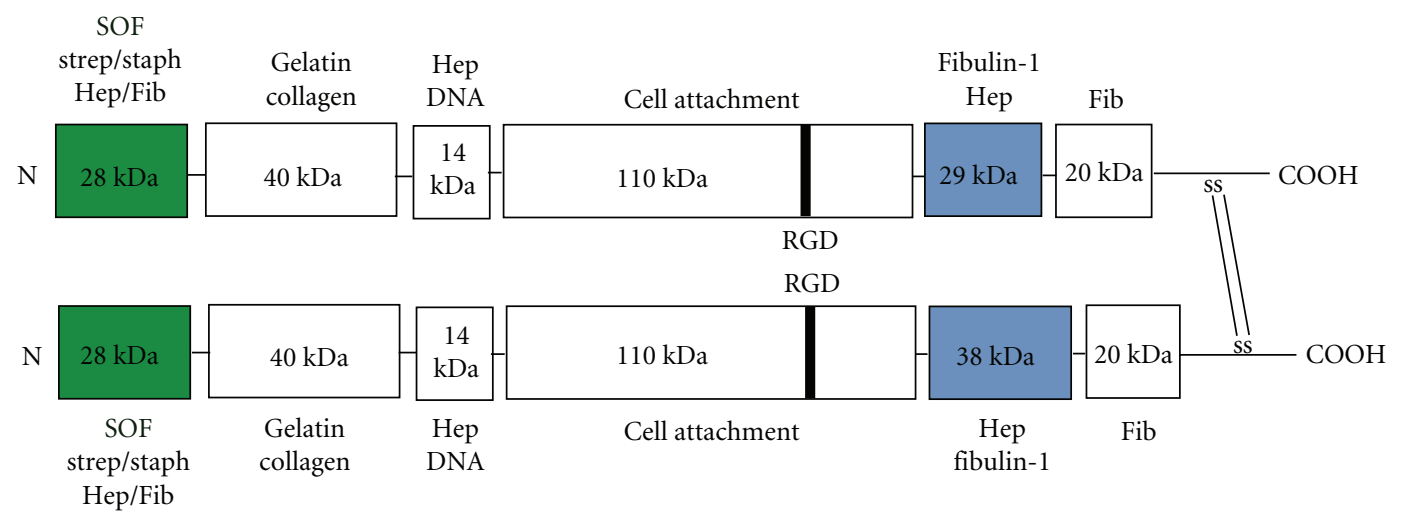

FIGURE 7: Model of fibronectin. Fibronectin (Fn) is a large, dimeric glycoprotein with multiple functional domains. The $28 \mathrm{kDa} \mathrm{N}$-terminal domain is the primary domain that interacts with most streptococci and staphylococci, but the collagen-binding domain may also interact with streptococci expressing protein $\mathrm{F}$ (or Sfb) [42]. SOF also binds to the N-terminal $28 \mathrm{kDa}$ domain of Fn via the C-terminal, repeating peptide of SOF [40]. Fibulin-1 binds to the C-terminal, heparin-binding domain of Fn [43]. The interaction of streptococci with the Nterminal domain of soluble Fn is thought to induce a conformational change that exposes the RGD domain [44]. The RGD domain of Fn can then bind to integrins on the surface of host cells and tether the bacteria to the surface. Such interactions induce actin polymerization and promote internalization of the bacteria [45]. Streptococci and SOF can also bind to Fn that has already bound to surfaces. Hep: heparin, Fib: fibrin/fibrinogen.

in cellular invasion of HEp-2 tissue culture cells, whereas inactivation of $s f b x$ had no effect on streptococcal invasion. Complementation of the SOF-negative defect with a sof plasmid conferred invasion levels that were higher than the parent strain. The higher degree of invasion was likely due to increased expression of sof as it was on a multicopy plasmid. These data suggest that it is SOF and not Sfbx that is the major contributor to streptococcal adhesion/invasion. That inactivation of SOF did not completely eliminate invasion is most probably due to the fact that $S$. pyogenes utilizes multiple adhesins to mediate attachment and invasion [46].

To further compare the roles that SOF and Sfbx may have in invasion, plasmids containing these genes were introduced into Lactobacillus lactis, a bacterium that does not bind fibronectin nor invade host cells. L. lactis expressing SOF had 1000-fold increase in host cell invasion as compared to only a 10 -fold increase in L. lactis expressing Sfbx [12]. These data clearly indicate that SOF mediates invasion of host cells and is superior to $\mathrm{Sfbx}$ in this function. Similar results were found when these two genes were introduced into M type $1 S$. pyogenes, which does not contain either of these genes [12].

The finding that Sfbx contains a fibronectin-binding domain homologous to that in SOF yet was not effective in promoting invasion suggested that fibronectin-binding domain of SOF may not be involved in host cell invasion by streptococci and indicates that $\mathrm{SOF} \Delta \mathrm{Fn}$ region is involved in this process. This hypothesis was confirmed by the findings that complementation of the SOF-negative defect with SOF $\Delta$ Fn fully restored wild-type levels of invasion [12]. These data indicate that SOF can mediate streptococcal invasion of host cells in a fibronectin-independent manner.

A host cell component(s) that could mediate this fibronectin-independent interaction with SOF was not identified in the above studies. Recently, we found that fibulin-1, a component of the extracellular matrix, binds to SOF and the fibronectin-binding domain of SOF was not required for this interaction [49]. Fibulin-1 bound to recombinant SOF from multiple serotypes suggesting that fibulin-1 binding domain is likely conserved among SOF from different serotypes. Insertional inactivation of sof diminished fibulin1 binding to $S$. pyogenes by $50 \%$. Purified SOF $\Delta$ Fn also blocked binding to $S$. pyogenes by $45 \%$. These findings suggest that $\mathrm{SOF}$ is a major but not the only streptococcal receptor for fibulin-1.

Thus, fibulin-1 could serve as a receptor for SOF that mediates adhesion of streptococci to surfaces of the host. Fibulin- 1 also binds fibronectin and these two proteins are found together in the extracellular matrix $[50,51]$. Interestingly, full length SOF containing the fibronectinbinding domain was found to dramatically enhance the interactions of SOF with a fibronectin-fibulin-collagen complex suggesting that such complexes may be involved in the adhesion of $S$. pyogenes to host surfaces [49]. It was proposed that interactions between collagen and fibronectin induced a conformational change in fibronectin that promoted interactions with fibulin-1 and SOF. An illustration of this complex is provided in Figure 9.

Fibrinogen is another host protein that interacts with SOF via the $\beta$-subunit of fibrinogen [52]. A SOF-negative mutant bound $50 \%$ less fibrinogen than did its wild-type parent indicating that $\mathrm{SOF}$ is a major fibrinogen-binding protein on $S$. pyogenes, but not the only one. This is not a surprising finding as other streptococcal proteins such as $\mathrm{M}$ proteins and M-related proteins also bind fibrinogen [53]. The fibrinogen-binding domain of SOF was localized to the same C-terminal repeat domain that binds fibronectin. Furthermore, fibrinogen blocked the binding of SOF to fibronectin, indicating that these two proteins bind to the same domain in SOF. Thus, whether it is fibronectin or fibrinogen that interacts with SOF will probably depend upon the local concentration of these two proteins. In blood, it is likely that fibrinogen will be the major binding protein 


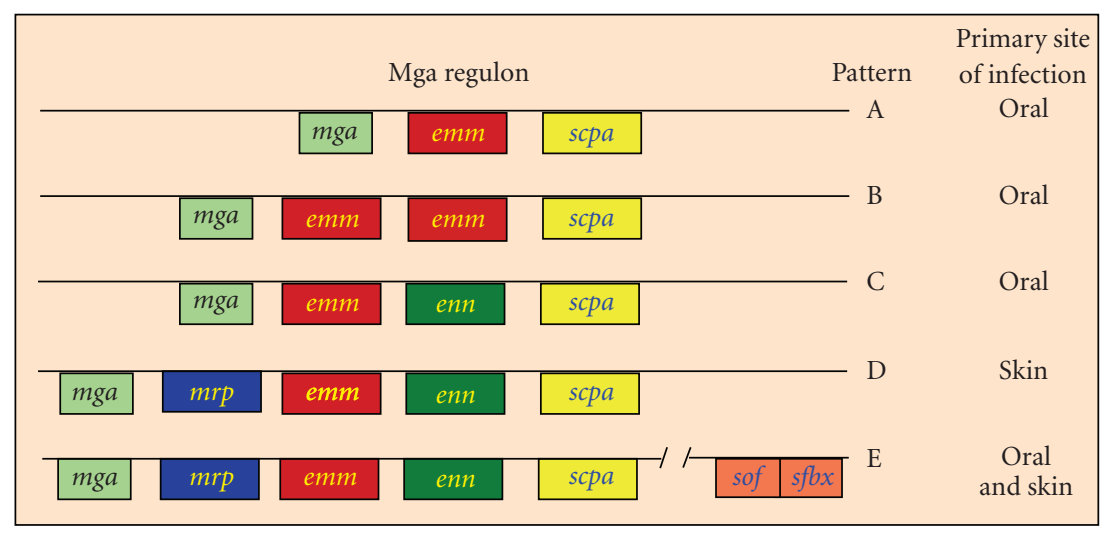

FIGURE 8: Variants of the Mga regulon and their relationship to preferential colonization of host sites. Mga (multigene activator) is a positive regulator of a number of streptococcal genes. The most prominent of these are the family of M proteins whose genes are tandemly linked. sof and $s f b x$ are bicistronic and are also regulated by Mga, but are located some distance away. emm encodes for M protein, $m r p$ encodes M-related proteins, enn encodes an M-like protein that binds IgA, and scpa encodes a C5a peptidase. Some serotypes contain only $m g a, e m m$, and scpa (pattern A). Other serotypes contain one or more of the remaining genes (patterns B-E). S. pyogenes with Mga patterns A, B, and C primarily infect oral tissues, whereas strains with pattern D are predominantly found in tissues of the skin. S. pyogenes with a pattern E Mga regulon are found at both oral and skin sites. Figure derived from data and classification scheme of Bessen and co-workers [47, 48].

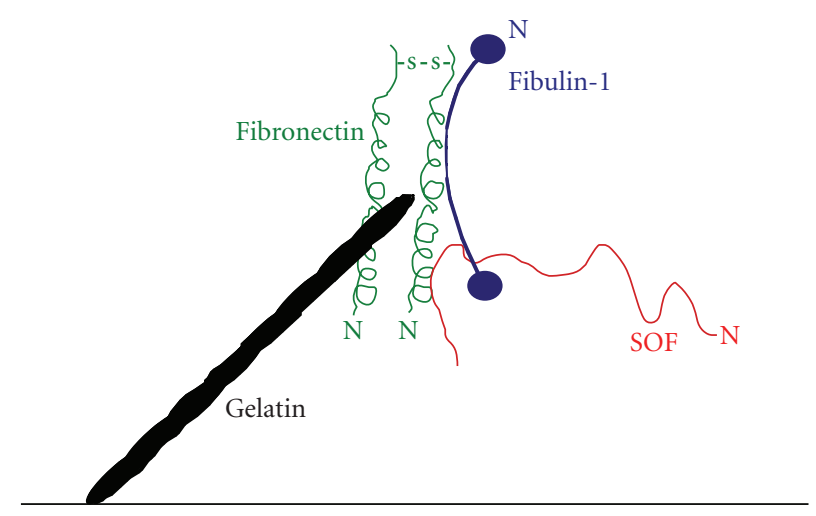

FIGURE 9: Model of quaternary complex between gelatin, fibronectin, fibulin-1, and SOF. Although SOF can bind to fibulin-1 independently of fibronectin, mixed binding experiments indicated that SOF binds much better to a complex of fibulin-1, fibronectin, and gelatin. Such complexes are possible because fibronectin contains independent binding sites for gelatin (collagen), fibulin1 , and SOF. Also SOF can react with fibulin-1 and fibronectin via independent binding domains. It is postulated that interactions between gelatin and fibronectin induces a conformational change in fibronectin that facilitates interactions with other ligands and SOF and enhances adhesion of streptococci to host surfaces. Reproduced from [49] with permission.

because the concentration of fibrinogen in blood is $\sim 10$ times higher than fibronectin. Fibrinogen is also found in the extracellular matrix and it also interacts with fibronectin and fibulin-1. This raises the question of whether such complexes between fibronectin, fibrinogen, and fibulin-1 could enhance interactions with SOF to promote streptococcal adhesion.

3.2.3. SOF Is a Virulence Determinant. A comparison of the survival curves of mice challenged intraperitoneally (IP) with an $\mathrm{M}$ type 2 strain of $S$. pyogenes and its SOF-negative mutant provided the first indication that $\mathrm{SOF}$ is a virulence factor [10]. Only $7 \%$ of mice challenged IP with wildtype $S$. pyogenes survived, whereas $80 \%$ of mice survived a challenge with its SOF-negative mutant. Complementation of the SOF defect with a plasmid expressing SOF fully restored virulence as none of the mice challenged with the complemented strain survived. Subsequent work indicated that insertional inactivation of sof also inactivated $s f b x$ [54], a gene for another fibronectin-binding protein that is cotranscribed with sof. However, it was demonstrated that the complemented strain expressed SOF and not Sfbx indicating that it is SOF that is responsible for restoring virulence [54]. An IP challenge of mice with either a wildtype M 49 strain of $S$. pyogenes or its Sfbx-negative mutant resulted in a death rate of $100 \%$, whereas $25 \%$ of the mice challenged with the SOF-negative mutant survived [12]. Heterologous expression of SOF in an M type 1 strain of $S$. pyogenes (an sof and $s f b x$ negative strain) increased mortality by $25 \%$ over that of the wild-type strain, whereas expression of Sfbx in this same strain had no effect on survival rate [12]. These data suggest that it is SOF and not Sfbx that is the major contributor to virulence of $S$. pyogenes.

Further support for SOF as a virulence determinant came from studies utilizing a murine model of necrotizing skin infections by $S$. pyogenes [12]. The skin lesions were larger in mice challenged with the wild-type strain as compared those challenged with the SOF-negative mutant. There was a 7.7-fold increase in the number of cfu obtained from tissues infected with wild-type strain as opposed to the SOFnegative mutant. These data again indicate that it is SOF and not $\mathrm{Sfbx}$ that is responsible for virulence and that SOF may contribute to virulence by enhancing streptococcal invasion of host tissues.

Another mechanism whereby SOF may contribute to virulence is by enhancing resistance to phagocytosis in 
blood. Inactivation of sof in M type 4 S. pyogenes decreased streptococcal survival and growth in human blood [53]. However, inactivation of sof in $\mathrm{M}$ type $2 \mathrm{~S}$. pyogenes had little effect on growth of $S$. pyogenes in human blood [10]. The reason for this difference is not clear. It is possible that the contribution of SOF2 to resistance to phagocytosis is too slight to make a significant impact on growth during the 3 hours of the bactericidal assay, but may be detectable during a longer time frame. Supporting this possibility is the finding that the SOF2-negative mutant was significantly less virulent than its parent in a mouse model of infection after 24 hours [10]. Furthermore, a small but consistent decrease in the growth of the SOF2-negative mutant in human blood was observed in subsequent repeat experiments (Courtney et al, unpublished data).

Another possibility for why inactivation of sof 2 lacked impact on growth in blood is that $\mathrm{M}$ type 2 streptococci may express other factors that provide a functional redundancy and thereby mask the loss of SOF2. It is clear, however, that SOF4 does contribute to resistance of $S$. pyogenes to phagocytosis in human blood. This contribution does not appear to involve regulating the deposition of complement onto the streptococcal surface because ablation of sof 4 had no impact on complement deposition. Thus, the antiphagocytic activity of SOF may depend on one of its known functions such as its ability to bind blood proteins such as fibronectin, fibrinogen, and fibulin-1, to bind to and disrupt HDL, or it may depend on some other, as yet unidentified mechanism(s). Further work needs to be done to define the mechanism(s) for resistance to phagocytosis and to determine if SOF has a role in resistance to phagocytosis in other serotypes of S. pyogenes.

S. suis also expresses SOF and inactivation of sof in a serotype 2 strain resulted in decreased virulence in piglets challenged intranasally [11]. Only one of the nine piglets (4-5 week old) challenged with wild-type S. suis survived, whereas all nine of the piglets challenged with the SOF-negative mutant survived. An interesting finding from this study was that SOF from S. suis did not bind fibronectin. There was no dramatic difference between parent and mutant strain in the colonization of tonsils of infected piglets. However, inactivation of SOF did appear to reduce the invasiveness of S. suis in 4-5 week-old piglets. The above findings have two implications. First, SOF may contribute to virulence of $S$. suis by increasing invasion; second, fibronectin-binding activity has no role in this activity.

The disruption of the structure of HDL by SOF may also contribute to the virulence of streptococci. In addition to its role in reverse cholesterol transport (see Section 7) HDL has an important role in controlling inflammation due to infections. Inflammation stimulated by bacterial components such as lipopolysaccharide or lipoteichoic acid is neutralized by HDL [55-57]. HDL reduced mortality in animal sepsis models and it is thought that HDL helps to control sepsis and shock by attenuating cytokine responses to infections [57]. Thus, the dissolution of HDL by SOF may alter the anti-inflammatory activities of HDL. However, the interactions between free apo A-I and the macrophage cholesterol exporter ABCA1 were recently found to not only enhance cholesterol transport but also to suppress inflammation [58]. Thus, disruption of HDL and the release of free apo A-I by SOF may actually promote an antiinflammatory response.

HDL also has a role in innate immunity via a number of antimicrobial agents. HDL contains apo A-I, apo L, and haptoglobin-related protein, which can kill trypanosomes [59]. HDL also contains the cathelicidin LL-37, an antimicrobial peptide that kills a variety of bacteria including $S$. pyogenes [60]. However, LL-37 in a free form can also be cytotoxic for host cells but this cytotoxicity is inhibited by lipoproteins in serum [61]. This may be why virtually all of LL-37 in blood is found associated with HDL, LDL, or VLDL. This raises the question of whether the interaction between SOF and HDL can release LL-37 and thereby promote its cytotoxic effects. HDL also contains a surprising number of complement regulatory proteins and protease inhibitors [62] but it is not known if the disruption of HDL's structure by SOF alters the functions of these proteins.

Although HDL is an antiatherogenic and anti-inflammatory lipoprotein [63], infections and inflammation can trigger events that not only lead to the loss of these properties of HDL but also convert HDL to a pro-inflammatory form that contributes to the pathogenesis of diseases [64-66]. Whether SOF may promote or inhibit this conversion process during infections remains to be determined

\section{Regulation of SOF Expression}

Expression of SOF in $S$. pyogenes is controlled by the multigene activator (Mga, formerly known as VirR and Mry), which regulates expression of a variety of virulence factors including M proteins, M-related proteins, Enn, Sic, and C5a peptidase [67-71]. The primary Mga regulon will vary among different serotypes as illustrated in Figure 8. In $S$. pyogenes, the sof gene is cotranscribed with $s f b x$ as a bicistronic message [24]. Mga is optimally expressed during $\log$ phase of growth and is activated by environmental signals such as elevated $\mathrm{CO}_{2}$, temperature, and iron-limiting conditions [72-74].

The Mga promoters are categorized based on the number and location of Mga-binding sites. The Mga promoter of $s o f-s f b x$ is a category B promoter with an Mga-binding site that is the most distal found to date while all category A promoters have a more proximal Mga-binding site [67]. Mga is considered to be a response regulator of a twocomponent system but its cognate sensor has not yet been identified. Although homologs of Mga have been found in $S$. dysgalactiae, it is not known if these also regulate expression of SOF [71].

\section{Distribution of SOF}

5.1. Prevalence and Distribution of SOF in Streptococci and Staphylococci. Table 2 lists the streptococcal and staphylococcal species that either contain the gene for SOF or that express a functional form of SOF. SOF has been found in streptococcal groups A, B, C, F, G, and R. Although SOF was found in some isolates of S. equi and S. agalactiae [75], 
TABLE 2: Prevalence of SOF among various bacteria.

\begin{tabular}{|c|c|c|}
\hline Bacteria & $\begin{array}{l}\text { Number of strains } \\
\text { positive for } \\
\text { SOF/total }^{\mathrm{a}}\end{array}$ & Reference \\
\hline $\begin{array}{l}\text { Group A streptococcus } \\
\text { S. pyogenes }\end{array}$ & $\begin{array}{l}52 / 117,77 / 125 \\
51 / 93\end{array}$ & {$[22,77,78]$} \\
\hline $\begin{array}{l}\text { Group B streptococcus } \\
\text { S. agalactiae }\end{array}$ & $0 / 14,0 / 30,5 / 18$ & {$[75,76], *$} \\
\hline $\begin{array}{l}\text { Group C streptococcus } \\
\text { S. equi }\end{array}$ & $4 / 15,0 / 20$ & {$[75,76]$} \\
\hline $\begin{array}{l}\text { Group D streptococcus } \\
\text { S. bovis, S. equinus, } \\
\text { Enterococcus faecalis b }\end{array}$ & $0 / 3$ & {$[76]$} \\
\hline $\begin{array}{l}\text { Group F streptococcus } \\
\text { S. anginosus }\end{array}$ & $2 / 5,0 / 5$ & {$[75,76]$} \\
\hline $\begin{array}{l}\text { Group G streptococcus } \\
\text { S. dysgalactiae, } S . \\
\text { arginosus, } S \text {. canis }\end{array}$ & $20 / 20,37 / 68,0 / 36$ & {$[29,75,76]$} \\
\hline $\begin{array}{l}\text { Group R streptococcus } \\
\text { S. suis }\end{array}$ & $33 / 36^{\mathrm{d}}$ & {$[30]$} \\
\hline Staphylococcus aureus & $0 / 5$ & * \\
\hline $\begin{array}{l}\text { Staphylococcus } \\
\text { epidermidis }\end{array}$ & $3 / 3$ & {$[79]$} \\
\hline
\end{tabular}

${ }^{a}$ positive for sof gene and/or for opacification of serum by extracts

${ }^{\mathrm{b}}$ formerly Streptococcus faecalis

${ }^{\mathrm{c}}$ formerly $\mathrm{S}$. milleri, it is a heterogeneous group that may also express group A, C F, or G antigens.

${ }^{d}$ approximately $70 \%$ of the 33 contained a nonfunctional sof gene.

* unpublished results from Courtney et al.

Top and Wannamaker [76] found no SOF in 14 isolates of group B or in 20 isolates of group C. We also did not find SOF in 30 isolates of group B (unpublished data). These findings suggest that additional tests need to done to determine if groups B and C do or do not express SOF. SOF was not found in streptococcal group D or in Staphylococcus aureus, but the number of isolates tested was low and further investigations should be done using a larger number of isolates. Staphylococcus epidermidis has also been found to express SOF but only three isolates were tested.

5.2. Streptococcus pyogenes. SOF is expressed by $\sim 45 \%$ of serotypes of S. pyogenes (Table 3 ) and by $\sim 50 \%$ of invasive isolates [21]. There are serotypes of $S$. pyogenes that primarily infect tissues of the oral mucosa and serotypes that primarily infect skin tissues. A subset of those serotypes that infect skin tissues express SOF and these serotypes also infect oral tissues (Figure 8). Approximately $60 \%$ of skin strains express SOF. One of the major differences between those serotypes infecting only the skin and those infecting both sites is the expression of SOF (Figure 8). Thus, acquisition of SOF by skin strains may have enhanced their ability to colonize the oral cavity.

5.3. Streptococcus dysgalactiae. A search for genes with similarity to sof suggested that $f n b A$ of $S$. dysgalactiae may also have the capacity to opacify serum. Cloning, expressing,
TABle 3: Distribution of SOF among M protein serotypes of $S$. pyogenes.

\begin{tabular}{ll}
\hline & $2,4,8,9,11,12,13,22,25,27,28,44,48$, \\
SOF-positive & $49,58,59,60,61,62,63,66,68,73,75$, \\
serotypes & $76,77,78,79,81,82,84,85,87,88,89$, \\
& $90,92,94,96,102,103,104,106,107$, \\
& $109,110,112,113,114,117,118,124$ \\
\hline & $1,3,5,6,14,15^{*}, 17,18,19,23,24,26$, \\
& $29,30,31,32,33,34,36,37,38,39,40$, \\
& $41,42,43,46,47,50,51,52,53,54,55$, \\
SOF-negative & $56,57,64,65,67,69,70,71,72,74,80$, \\
serotypes & $83,86,91,93,95,97,98,99,100,101$, \\
& $105,108,111,115,116,119,120,121$, \\
& 122,123 \\
\hline
\end{tabular}

Data from Johnson et al. [77] and Beall et al. [21]. Streptococci are considered positive if SOF is expressed and/or the sof gene is present. Note that M types 7, 10, 16, 20,21, 35, and 45 do not exist as these were subsequently found not to be group A streptococci.

*There are conflicting reports regarding whether M15 serotypes are negative or positive for SOF $[77,80]$.

and testing the recombinant protein of this gene confirmed that FnbA from $S$. dysgalactiae is in fact an opacity factor $[10,27]$. FnbA of $S$. dysgalactiae should not be confused with FnbA of $S$. aureus as no opacifying activity has been found in strains of $S$. aureus that have been tested and there is little similarity between these two proteins except for their ability to bind fibronectin. Southern blot analyses indicated that $f n b A$ was present in all 20 of the clinical isolates of $S$. dysgalactiae tested [29]. FnbA that opacified horse serum was expressed by $S$. dysgalactiae, but unlike most strains of $S$. pyogenes, only the cell bound form was found and no activity was found in culture medium [10]. Although these findings indicate that $f n b A$ is expressed in S. dysgalactiae, only one isolate was tested and additional isolates need to be examined to determine if expression of SOF is a common trait.

5.4. Streptococcus suis. The group R streptococcus, S. suis, also expresses SOF $[11,30]$. As one might guess from its name, $S$. suis is primarily a swine pathogen but it can also cause infections in humans [81]. Serotype 2 strains of $S$. suis are the major cause of infections in both swine and humans. The handling of pigs or pig products and eating undercooked pork is associated with high risk for infections. S. suis causes similar diseases in pigs and humans such as meningitis, septicemia, pneumonia, endocarditis, arthritis, and sudden death. SOF was identified as a virulence factor in a serotype 2 strain of $S$. suis using a piglet model of infection [11]. The sof gene was found in 33 of 36 of strains isolated. However, about $70 \%$ of these strains did not express a functional form of SOF due to point mutations or gene rearrangements [30]. Four allelic variants of sof were found in S. suis [30]. Type 1 and type 2 variants were functionally expressed, whereas the type 3 and type 4 variants were not expressed. Type 3 variants contained a point mutation and type 4 variants contained insertional elements or exhibited gene rearrangement. The majority of $S$. suis isolates that expressed SOF contained the type 1 allelic variant of sof [30] 


\section{Vaccine Potential of SOF}

The potential of SOF as a vaccine for group A streptococcal infections was first highlighted by the findings that rabbit antisera against SOF from an $M$ type 2 strain of $S$. pyogenes not only opsonized and killed $\mathrm{M}$ type $2 \mathrm{~S}$. pyogenes but also opsonized and killed heterologous $\mathrm{M}$ types 4 and 28 of S. pyogenes in human blood [13]. Opsonization and killing of $S$. pyogenes in human blood is a key indicator of an effective vaccine against group A streptococci [82]. These findings suggest that there are common, protective epitopes among SOF from different serotypes that may be useful in developing vaccines and that immunization with these common protective epitopes may confer protection against a wide variety of SOF-positive serotypes. Furthermore, antibodies against SOF that were purified from human serum by SOF-affinity chromatography effectively killed $S$. pyogenes in bactericidal assays indicating that SOF can elicit a protective immune response in humans [13].

In toxicity studies, mice were intravenously injected with $100 \mu \mathrm{g}$ of SOF or a truncated peptide of SOF and no overt signs of toxicity were seen [13]. These same mice then received an IP injection of $100 \mu \mathrm{g}$ of SOF and again, without overt signs of toxicity. Subsequent experiments indicated that these mice were protected against an IP challenge with $S$. pyogenes. To determine if the fibronectinbinding domain of SOF is required to elicit a protective immune response, mice were immunized subcutaneously with $25 \mu \mathrm{g}$ of SOF $\Delta \mathrm{Fn}$, boosted with $25 \mu \mathrm{g}$ of SOF $\Delta \mathrm{Fn}$ two weeks later, and then challenged IP with $S$. pyogenes. The results indicated that subcutaneous immunization with SOF $\triangle F n$ evoked high titers against SOF in mice and provided significant protection against challenging IP infections [13]. Thus, the fibronectin-binding domain of SOF is not required to stimulate a protective immune response. This does not mean that the fibronectin-binding domain of SOF could not contribute to a protective immune response but that it is not required. Indeed, others have reported that immunization of mice with the fibronectin-binding domain of SfbI provided protection against challenge infections of $S$. pyogenes [83].

Immunization of mice can evoke a strong antibody response that can provide protection by several different mechanisms. Antibodies may block adhesion to host surfaces by binding to a surface antigen and interfering with its ability to interact with host receptors. Antibodies may also bind to and neutralize a virulence factor or antibodies may opsonize bacteria. In the case above where mice were subcutaneously immunized with $\mathrm{SOF} \Delta \mathrm{Fn}$, an antiadhesive effect can be excluded because the mice were challenged IP which circumvents the stages of adhesion and colonization. It is possible that protection was afforded by antibodies that neutralized the function of SOF. However, this is unlikely because we have not been able to evoke neutralizing antibodies in any of the animals immunized with SOF even though high-titered antisera were developed against SOF. The difficulty in developing neutralizing antiserum against SOF has been noted by other investigators [28].
Thus, the stimulation of opsonic antibodies is the most likely mechanism for providing protection.

Schulze et al. [84] reported that intranasal immunization of mice with SOF failed to protect against a lethal mucosal challenge. These findings suggest that the intranasal route for administering SOF is not the optimal route for stimulating a protective immune response, whereas a protective immune response was evoked by the subcutaneous route. Further work should be done to determine if other immunization routes such as intramuscular might be more effective.

The above findings indicate that SOF contains common epitopes that can evoke opsonic antibodies that may protect against infections from a variety of serotypes of SOF-positive $S$. pyogenes. Furthermore, anti-SOF serum enhanced the effectiveness of antiserum against $M$ protein to opsonize and kill $S$. pyogenes [13]. This is particularly relevant when one considers that $\mathrm{M}$ proteins from some serotypes did not elicit a very effective immune response and these serotypes were primarily SOF-positive [85]. Current vaccine efforts have focused primarily on $\mathrm{M}$ proteins, but the more than 100 different types of $\mathrm{M}$ proteins complicate vaccine construction and there are some serotypes whose protective antigens have not been identified. Thus, inclusion of common, protective epitopes of SOF may enhance the effectiveness of $\mathrm{M}$ protein-based vaccines and broaden their coverage of serotypes.

\section{SOF as a Therapeutic to Enhance Reverse Cholesterol Transport}

High-plasma cholesterol levels are considered to be a major risk factor for cardiovascular disease and much effort has been given to developing therapies to control cholesterol concentrations. An important target in this fight to control cholesterol is the pathway for reverse cholesterol transport (RCT). RCT is the major pathway for removing cholesterol from peripheral tissues and transporting it to the liver for disposal (Figure 10). Defects in this pathway can lead to the accumulation of cholesterol in macrophages that line blood vessels resulting in plaque formation and subsequent atherosclerosis. Thus, therapies that can enhance RCT would be beneficial in controlling atherosclerosis.

SOF is a heterodivalent fusogen that binds and crosslinks HDL and induces the formation of three major products: free apo A-I, CERM particles, and a neo-HDL particle (Figure 5). All three of these products promote RCT. Free apo A-I is known to be a potent stimulator of RCT via ABCA1 [89]. Our studies indicate that neo-HDL promotes efflux of free cholesterol from tissues at a faster rate than HDL [88] and this may be due to a new conformational state of apo A-I that is stabilized by the high percentage of phospholipids in neo-HDL [90]. In addition, neo-HDL enhances the activity of lecithin:cholesterol acyl transferase (LCAT) better than HDL and results in an increase in cholesterol esters in CERM particles that may aid in removal of cholesterol by hepatic receptors. Preliminary studies indicate that $\mathrm{rSOF}$ can induce opacification of murine HDL in vivo. What is even more promising is that SOF reduced plasma cholesterol 


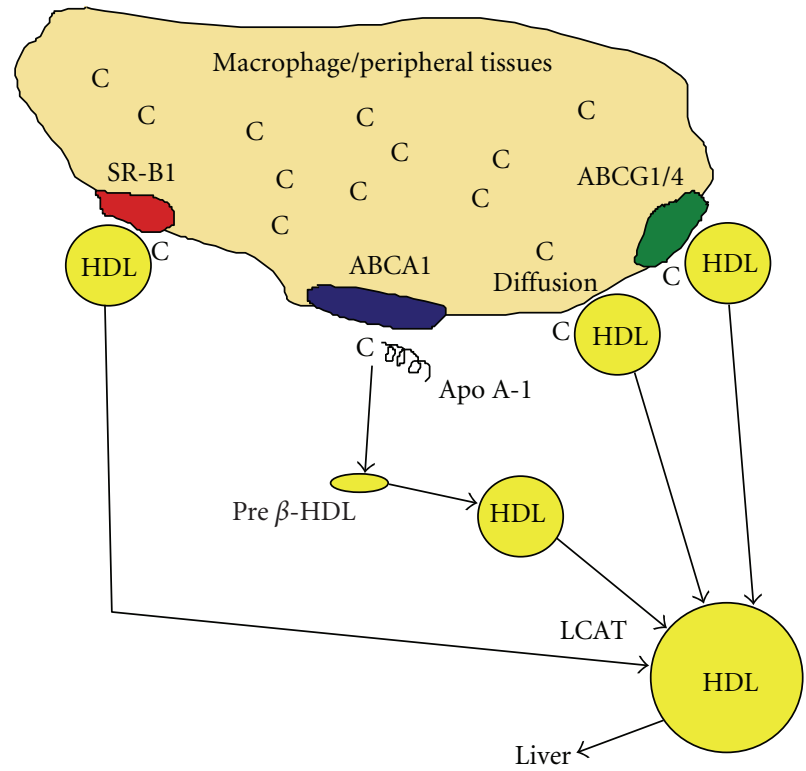

Figure 10: Reverse cholesterol transfer pathway (RCT). RCT is the major pathway for transfer of excess cholesterol (C) from peripheral tissues to the liver for disposal as bile. High levels of cholesterol can be toxic and the accumulation of cholesterol (C) in macrophages lining the blood vessels transforms these cells to foam cells leading to the development of plaque and atherosclerosis. Cholesterol is removed from these tissues and transferred to HDL by interactions with ATP binding cassette receptors ABCA1, ABCG1/4, and SR$\mathrm{B} 1$ or by diffusion. The interaction between ABCA1 and apo A$\mathrm{I}$ is the dominant pathway for removal of excess cholesterol from macrophages followed by an interaction between HDL and ABCG1. Together these two receptors account for about $70 \%$ of the efflux of excess cholesterol [86]. The size of HDL is modulated as its load of cholesterol increases and by interactions with various plasma factors such as lecithin cholesterol acyltransferase (LCAT) [87]. Free cholesterol removed from these tissues is esterified by LCAT and subsequently removed by liver cells by interactions with HDL. SOF enhances this process in several ways [88]. First, it releases free apo A-I, which is a better acceptor of free cholesterol than HDL. Secondly, it forms neo-HDL, a particle that is similar to pre- $\beta$ HDL, which is also a better acceptor of cholesterol than HDL. Thirdly, SOF enhances cholesterol esterification, which may allow a more efficient uptake of cholesterol by the liver.

by $50 \%$ in these mice [91]. These observations suggest that the reaction of $\mathrm{rSOF}$ with HDL may have potential to therapeutically enhance RCT and reduce high levels of plasma cholesterol that are a leading cause of cardiovascular disease.

SOF is a virulence factor and it is logical to question the practicality of using it as a therapeutic. However, there are examples of bacterial virulence determinants and toxins that are safely used as therapeutics. Anthrax toxins have been used to target and kill cancer cells and the isolated toxins do not pose a health hazard [92]. The botulinum toxin (Botox) has been used for years as a muscle relaxant and treatment for facial wrinkles [93]. Streptokinase is a streptococcal virulence factor that has long been used in humans as a thrombolytic agent [94]. Thus, while bacterial virulence factors may contribute to the pathogenesis of infections, the isolated virulence factor may not necessarily be harmful when used properly in a purified form. Previous studies indicated that an intravenous injection of $100 \mu \mathrm{g}$ of rSOF in mice was well tolerated and had no discernable toxic effects [13] and, as noted above, the cholesterol levels were dramatically reduced in mice receiving minute quantities $(\leq 1 \mu \mathrm{g}$ per mouse) of SOF. These are preliminary data and more definitive experiments will be required to validate these initial findings and to determine the relative beneficial/adverse effects of the interactions between SOF and HDL

\section{Future Considerations}

It is clear that $\mathrm{SOF}$ is a virulence determinant as SOF was found to contribute to virulence in 3 different models of infection. However, it is not clear which function(s) of SOF is mainly responsible for this virulence. Mutants defective in each function of SOF (opacification, fibronectin/fibrinogen binding, fibulin-1 binding, etc.) need to be engineered and tested in appropriate animal models to determine which function or combination of functions contributes to virulence. The role of vWFA domain and its MIDAS motif in these activities should also be investigated.

As a corollary to these studies, the crystal structure of SOF needs to be resolved. Establishing the crystal structure of SOF would help to pinpoint areas for targeting to create mutant forms of SOF. This information may be used to engineer forms of SOF that are deficient in activities contributing to virulence while still maintaining ability to opacify HDL. In addition to loss of function studies, it may be possible to use the structural information to engineer SOF mutants that have a gain of function such as enhanced ability to opacify serum and thereby to increase concentrations of the reactants of rSOF-HDL interactions to more effectively control cholesterol levels via RCT.

The potential of SOF as a vaccine needs to be further explored. Particularly, in regard to defining the common, protective epitopes of SOF and determining if a combination of a SOF vaccine with other vaccines such as $M$ protein vaccines would broaden coverage of serotypes and enhance efficacy. SOF is also expressed by animal pathogens and demonstrated to be a virulence factor in one of these pathogens but there has been no investigation into its vaccine potential in animals. Thus, there is a clear need for further studies on SOF and hopefully, the next decade will bring exciting, new discoveries about the structure and function of SOF and will lead to new, highly effective vaccines and therapeutics.

\section{Acknowledgments}

The work of the authors was supported by funds from the Department of Veterans Affairs (Harry S. Courtney) and from the National Institutes of Health (HL-30914 and HL56865 to Henry J. Pownall). 


\section{References}

[1] H. K. Ward and G. V. Rudd, "Studies on haemolytic streptococci from human sources," Australian Journal of Experimental Biology \& Medical Science, vol. 16, pp. 181-192, 1938.

[2] E. Krumwiede, "Studies on a lipoproteinase of group A streptococci," The Journal of Experimental Medicine, vol. 100, no. 6, pp. 629-639, 1954.

[3] R. Rowen, "The release of cholesterol esters from serum lipoproteins by extracts of certain group A streptococci," Journal of Experimental Medicine, vol. 114, pp. 807-823, 1961.

[4] R. Rowen and J. Martin, "Enhancement of cholesterol esterification in serum by an extract of group-A streptococcus," Biochimica et Biophysica Acta, vol. 70, pp. 396-405, 1963.

[5] G. A. Saravani and D. R. Martin, "Opacity factor from group A streptococci is an apoproteinase," FEMS Microbiology Letters, vol. 68 , no. 1-2, pp. 35-39, 1990.

[6] H. S. Courtney, Y.-M. Zhang, M. W. Frank, and C. O. Rock, "Serum opacity factor, a streptococcal virulence factor that binds to apolipoproteins A-I and A-II and disrupts high density lipoprotein structure," Journal of Biological Chemistry, vol. 281, no. 9, pp. 5515-5521, 2006.

[7] B. K. Gillard, H. S. Courtney, J. B. Massey, and H. J. Pownall, "Serum opacity factor unmasks human plasma highdensity lipoprotein instability via selective delipidation and apolipoprotein A-I desorption," Biochemistry, vol. 46, no. 45, pp. 12968-12978, 2007.

[8] M. W. Cunningham, "Pathogenesis of group a streptococcal infections," Clinical Microbiology Reviews, vol. 13, no. 3, pp. 470-511, 2000.

[9] H. S. Courtney, D. L. Hasty, and J. B. Dale, "Molecular mechanisms of adhesion, colonization, and invasion of group A streptococci," Annals of Medicine, vol. 34, no. 2, pp. 77-87, 2002.

[10] H. S. Courtney, D. L. Hasty, Y. Li, H. C. Chiang, J. L. Thacker, and J. B. Dale, "Serum opacity factor is a major fibronectinbinding protein and a virulence determinant of $\mathrm{M}$ type 2 Streptococcus pyogenes," Molecular Microbiology, vol. 32, no. 1, pp. 89-98, 1999.

[11] C. G. Baums, U. Kaim, M. Fulde, G. Ramachandran, R. Goethe, and P. Valentin-Weigand, "Identification of a novel virulence determinant with serum opacification activity in Streptococcus suis," Infection and Immunity, vol. 74, no. 11, pp. 6154-6162, 2006.

[12] A. M. Timmer, S. A. Kristian, V. Datta et al., "Serum opacity factor promotes group A streptococcal epithelial cell invasion and virulence," Molecular Microbiology, vol. 62, no. 1, pp. 1525, 2006.

[13] H. S. Courtney, D. L. Hasty, and J. B. Dale, "Serum opacity factor (SOF) of Streptococcus pyogenes evokes antibodies that opsonize homologous and heterologous sof-positive serotypes of group A streptococci," Infection and Immunity, vol. 71, no. 9, pp. 5097-5103, 2003.

[14] C. D. Rehder, D. R. Johnson, and E. L. Kaplan, "Comparison of methods for obtaining serum opacity factor from group A streptococci," Journal of Clinical Microbiology, vol. 33, no. 11, pp. 2963-2967, 1995.

[15] D. R. Johnson and E. L. Kaplan, "Microtechnique for serum opacity factor characterization of group A streptococci adaptable to the use of human sera," Journal of Clinical Microbiology, vol. 26, no. 10, pp. 2025-2030, 1988.

[16] J. V. Rakonjac, J. C. Robbins, and V. A. Fischetti, "DNA sequence of the serum opacity factor of group A streptococci: identification of a fibronectin-binding repeat domain," Infection and Immunity, vol. 63, no. 2, pp. 622-631, 1995.

[17] C. M. Gillen, R. J. Towers, D. J. McMillan et al., "Immunological response mounted by Aboriginal Australians living in the Northern Territory of Australia against Streptococcus pyogenes serum opacity factor," Microbiology, vol. 148, no. 1, pp. 169-178, 2002.

[18] J. P. Widdowson, W. R. Maxted, and D. L. Grant, "The production of opacity in serum by group A streptococci and its relationship withthe presence of M antigen," Journal of General Microbiology, vol. 61, no. 3, pp. 343-353, 1970.

[19] D. R. Johnson and E. L. Kaplan, "A review of the correlation of T-agglutination patterns and M-protein typing and opacity factor production in the identification of group A streptococci," Journal of Medical Microbiology, vol. 38, no. 5, pp. 311315, 1993.

[20] W. R. Maxted, J. P. Widdowson, C. A. Fraser, L. C. Ball, and D. C. Bassett, "The use of the serum opacity reaction in the typing of group-A streptococci," Journal of Medical Microbiology, vol. 6, no. 1, pp. 83-90, 1973.

[21] B. Beall, G. Gherardi, M. Lovgren, R. R. Facklam, B. A. Forwick, and G. J. Tyrrell, "emm and sof gene sequence variation in relation to serological typing of opacity-factorpositive group A streptococci," Microbiology, vol. 146, no. 5, pp. 1195-1209, 2000.

[22] B. Kreikemeyer, S. R. Talay, and G. S. Chhatwal, "Characterization of a novel fibronectin-binding surface protein in group A streptococci," Molecular Microbiology, vol. 17, no. 1, pp. 137145, 1995.

[23] S. B. Beres, E. W. Richter, M. J. Nagiec et al., "Molecular genetic anatomy of inter- and intraserotype variation in the human bacterial pathogen group A Streptococcus," Proceedings of the National Academy of Sciences of the United States of America, vol. 103, no. 18, pp. 7059-7064, 2006.

[24] A. Jeng, V. Sakota, Z. Li, V. Datta, B. Beall, and V. Nizet, "Molecular genetic analysis of a group A Streptococcus operon encoding serum opacity factor and a novel fibronectinbinding protein, SfbX," Journal of Bacteriology, vol. 185, no. 4, pp. 1208-1217, 2003.

[25] N. M. Green, S. Zhang, S. F. Porcella et al., "Genome sequence of a serotype M28 strain of group A Streptococcus: potential new insights into puerperal sepsis and bacterial disease specificity," Journal of Infectious Diseases, vol. 192, no. 5, pp. 760-770, 2005.

[26] W. M. McShan, J. J. Ferretti, T. Karasawa et al., "Genome sequence of a nephritogenic and highly transformable M49 strain of Streptococcus pyogenes," Journal of Bacteriology, vol. 190, no. 23, pp. 7773-7785, 2008.

[27] V. Katerov, P.-E. Lindgren, A. A. Totolian, and C. Schalén, "Streptococcal opacity factor: a family of bifunctional proteins with lipoproteinase and fibronectin-binding activities," Current Microbiology, vol. 40, no. 3, pp. 149-156, 2000.

[28] B. Kreikemeyer, D. R. Martin, and G. S. Chhatwal, "SfbII protein, a fibronectin binding surface protein of group A streptococci, is a serum opacity factor with high serotypespecific apolipoproteinase activity," FEMS Microbiology Letters, vol. 178, no. 2, pp. 305-311, 1999.

[29] P.-E. Lindgren, M. J. McGavin, C. Signas et al., "Two different genes coding for fibronectin-binding proteins from Streptococcus dysgalactiae. The complete nucleotide sequences and characterization of the binding domains," European Journal of Biochemistry, vol. 214, no. 3, pp. 819-827, 1993.

[30] D. Takamatsu, M. Osaki, P. Tharavichitkul, S. Takai, and T. Sekizaki, "Allelic variation and prevalence of serum opacity 
factor among the Streptococcus suis population," Journal of Medical Microbiology, vol. 57, no. 4, pp. 488-494, 2008.

[31] J. E. Wertz, K. F. McGregor, and D. E. Bessen, "Detecting key structural features within highly recombined genes," PLoS Computational Biology, vol. 3, no. 1, article e14, 2007.

[32] H. Ton-That, L. A. Marraffini, and O. Schneewind, "Protein sorting to the cell wall envelope of Gram-positive bacteria," Biochimica et Biophysica Acta, vol. 1694, no. 1-3, pp. 269-278, 2004.

[33] C. A. Whittaker and R. O. Hynes, "Distribution and evolution of von Willebrand/integrin A domains: widely dispersed domains with roles in cell adhesion and elsewhere," Molecular Biology of the Cell, vol. 13, no. 10, pp. 3369-3387, 2002.

[34] G. A. Saravani and D. R. Martin, "Characterisation of opacity factor from group-A streptococci," Journal of Medical Microbiology, vol. 33, no. 1, pp. 55-60, 1990.

[35] H. J. Pownall, "Remodeling of human plasma lipoproteins by detergent perturbation,” Biochemistry, vol. 44, no. 28 , pp. 9714-9722, 2005.

[36] H. J. Pownall, B. D. Hosken, B. K. Gillard, C. L. Higgins, H. Y. Lin, and J. B. Massey, "Speciation of human plasma highdensity lipoprotein (HDL): HDL stability and apolipoprotein A-I partitioning," Biochemistry, vol. 46, no. 25, pp. 7449-7459, 2007.

[37] R. Mehta, D. L. Gantz, and O. Gursky, "Human plasma highdensity lipoproteins are stabilized by kinetic factors," Journal of Molecular Biology, vol. 328, no. 1, pp. 183-192, 2003.

[38] M. Han, B. K. Gillard, H. S. Courtney et al., "Disruption of human plasma high-density lipoproteins by streptococcal serum opacity factor requires labile apolipoprotein A-I," Biochemistry, vol. 48, no. 7, pp. 1481-1487, 2009.

[39] C. Rosales, B. K. Gillard, H. S. Courtney, F. Blanco-Vaca, and H. J. Pownall, "Apolipoprotein modulation of streptococcal serum opacity factor activity against human plasma highdensity lipoproteins," Biochemistry, vol. 48, no. 33, pp. 8070 8076, 2009.

[40] S. Oehmcke, A. Podbielski, and B. Kreikemeyer, "Function of the fibronectin-binding serum opacity factor of Streptococcus pyogenes in adherence to epithelial cells," Infection and Immunity, vol. 72, no. 7, pp. 4302-4308, 2004.

[41] C. M. Gillen, H. S. Courtney, K. Schulze et al., "Opacity factor activity and epithelial cell binding by the serum opacity factor protein of Streptococcus pyogenes are functionally discrete," Journal of Biological Chemistry, vol. 283, no. 10, pp. 63596366, 2008.

[42] S. R. Talay, A. Zock, M. Rohde et al., "Co-operative binding of human fibronectin to Sfbl protein triggers streptococcal invasion into respiratory epithelial cells," Cellular Microbiology, vol. 2, no. 6, pp. 521-535, 2000.

[43] K. Balbona, H. Tran, S. Godyna, K. C. Ingham, D. K. Strickland, and W. S. Argraves, "Fibulin binds to itself and to the carboxyl-terminal heparin-binding region of fibronectin," Journal of Biological Chemistry, vol. 267, no. 28, pp. 2012020125, 1992.

[44] B. R. Tomasini-Johansson, N. R. Kaufman, M. G. Ensenberger, V. Ozeri, E. Hanski, and D. F. Mosher, "A 49-residue peptide from adhesin F1 of Streptococcus pyogenes inhibits fibronectin matrix assembly," Journal of Biological Chemistry, vol. 276, no. 26, pp. 23430-23439, 2001.

[45] P. E. Dombek, D. Cue, J. Sedgewick et al., "High-frequency intracellular invasion of epithelial cells by serotype M1 group A streptococci: M1 protein-mediated invasion and cytoskeletal rearrangements," Molecular Microbiology, vol. 31, no. 3, pp. 859-870, 1999.
[46] H. S. Courtney and A. Podbielski, "Group A Streptococcal invasion of host cells," in Bacterial Invasion of Host Cells, R. J. Lamont, Ed., pp. 239-273, Cambridge University Press, Cambridge, UK, 2004.

[47] A. Kalia and D. E. Bessen, "Natural selection and evolution of Streptococcal virulence genes involved in tissue-specific adaptations," Journal of Bacteriology, vol. 186, no. 1, pp. 110121, 2004.

[48] D. E. Bessen, C. M. Sotir, T. L. Readdy, and S. K. Hollingshead, "Genetic correlates of throat and skin isolates of group A streptococci," Journal of Infectious Diseases, vol. 173, no. 4, pp. 896-900, 1996.

[49] H. S. Courtney, Y. Li, W. O. Twal, and W. S. Argraves, "Serum opacity factor is a streptococcal receptor for the extracellular matrix protein fibulin-1," Journal of Biological Chemistry, vol. 284, no. 19, pp. 12966-12971, 2009.

[50] W. S. Argraves, L. M. Greene, M. A. Cooley, and W. M. Gallagher, "Fibulins: physiological and disease perspectives," EMBO Reports, vol. 4, no. 12, pp. 1127-1131, 2003.

[51] S. de Vega, T. Iwamoto, and Y. Yamada, "Fibulins: multiple roles in matrix structures and tissue functions," Cellular and Molecular Life Sciences, vol. 66, no. 11-12, pp. 1890-1902, 2009.

[52] H. S. Courtney, J. B. Dale, and D. L. Hasty, "Mapping the fibrinogen-binding domain of serum opacity factor of group A streptococci," Current Microbiology, vol. 44, no. 4, pp. 236240, 2002.

[53] H. S. Courtney, D. L. Hasty, and J. B. Dale, "Anti-phagocytic mechanisms of Streptococcus pyogenes: binding of fibrinogen to M-related protein," Molecular Microbiology, vol. 59, no. 3, pp. 936-947, 2006.

[54] H. S. Courtney, S. K. Nishimoto, J. B. Dale, D. L. Hasty, and K. H. Schmidt, "Relative contributions of Serum Opacity Factor (SOF) and Streptococcal fibronectin-binding protein $\mathrm{x}(\mathrm{Sfbx})$ to the virulence of group A streptococci," Current Trends in Microbiology, vol. 1, pp. 87-96, 2004.

[55] T. S. Parker, D. M. Levine, J. C. C. Chang, J. Laxer, C. C. Coffin, and A. L. Rubin, "Reconstituted high-density lipoprotein neutralizes gram-negative bacterial lipopolysaccharides in human whole blood," Infection and Immunity, vol. 63, no. 1, pp. 253-258, 1995.

[56] C. Grunfeld, M. Marshall, J. K. Shigenaga, A. H. Moser, P. Tobias, and K. R. Feingold, "Lipoproteins inhibit macrophage activation by lipoteichoic acid," Journal of Lipid Research, vol. 40, no. 2, pp. 245-252, 1999.

[57] A. Wu, C. J. Hinds, and C. Thiemermann, "High-density lipoproteins in sepsis and septic shock: metabolism, actions, and therapeutic applications," Shock, vol. 21, no. 3, pp. 210221, 2004.

[58] C. Tang, Y. Liu, P. S. Kessler, A. M. Vaughan, and J. F. Oram, "The macrophage cholesterol exporter ABCA1 functions as an anti-inflammatory receptor," Journal of Biological Chemistry, vol. 284, no. 47, pp. 32336-32343, 2009.

[59] M. P. Molina-Portela, M. Samanovic, and J. Raper, "Distinct roles of apolipoprotein components within the trypanosome lytic factor complex revealed in a novel transgenic mouse model," Journal of Experimental Medicine, vol. 205, no. 8, pp. 1721-1728, 2008.

[60] V. Nizet, T. Ohtake, X. Lauth et al., "Innate antimicrobial peptide protects the skin from invasive bacterial infection," Nature, vol. 414, no. 6862, pp. 454-457, 2001.

[61] Y. E. Lau, D. M. E. Bowdish, C. Cosseau, R. E. W. Hancock, and D. J. Davidson, "Apoptosis of airway epithelial cells: human serum sensitive induction by the cathelicidin LL-37," American 
Journal of Respiratory Cell and Molecular Biology, vol. 34, no. 4, pp. 399-409, 2006.

[62] T. Vaisar, S. Pennathur, P. S. Green et al., "Shotgun proteomics implicates protease inhibition and complement activation in the antiinflammatory properties of HDL," Journal of Clinical Investigation, vol. 117, no. 3, pp. 746-756, 2007.

[63] K.-A. Rye and P. J. Barter, "Antiinflammatory actions of HDL: a new insight," Arteriosclerosis, Thrombosis, and Vascular Biology, vol. 28, no. 11, pp. 1890-1891, 2008.

[64] W. Khovidhunkit, M.-S. Kim, R. A. Memon et al., "Effects of infection and inflammation on lipid and lipoprotein metabolism: mechanisms and consequences to the host," Journal of Lipid Research, vol. 45, no. 7, pp. 1169-1196, 2004.

[65] A. Urundhati, Y. Huang, J. A. Lupica, J. D. Smith, J. A. DiDonato, and S. L. Hazen, "Modification of high density lipoprotein by myeloperoxidase generates a pro-inflammatory particle," Journal of Biological Chemistry, vol. 284, no. 45, pp. 30825-30835, 2009.

[66] M. Navab, G. M. Anantharamaiah, S. T. Reddy, B. J. Van Lenten, B. J. Ansell, and A. M. Fogelman, "Mechanisms of disease: proatherogenic HDL_-an evolving field," Nature Clinical Practice Endocrinology and Metabolism, vol. 2, no. 9, pp. 504-511, 2006.

[67] A. C. Almengor, M. S. Walters, and K. S. McIver, "Mga is sufficient to activate transcription in vitro of sof-sfbX and other Mga-regulated virulence genes in the group A streptococcus," Journal of Bacteriology, vol. 188, no. 6, pp. 2038-2047, 2006.

[68] L. A. McLandsborough and P. P. Cleary, "Insertional inactivation of virR in Streptococcus pyogenes M49 demonstrates that virR functions as a positive regulator of ScpA, FcRA, OF, and M protein," FEMS Microbiology Letters, vol. 128, no. 1, pp. 4551, 1995.

[69] A. Podbielski, A. Flosdorff, and J. Weber-Heynemann, "The group A streptococcal virR49 gene controls expression of four structural vir regulon genes," Infection and Immunity, vol. 63, no. 1, pp. 9-20, 1995.

[70] M. G. Caparon and J. R. Scott, "Identification of a gene that regulates expression of $\mathrm{M}$ protein, the major virulence determinant of group A streptococci," Proceedings of the National Academy of Sciences of the United States of America, vol. 84, no. 23, pp. 8677-8681, 1987.

[71] B. Kreikemeyer, K. S. McIver, and A. Podbielski, "Virulence factor regulation and regulatory networks in Streptococcus pyogenes and their impact on pathogen-host interactions," Trends in Microbiology, vol. 11, no. 5, pp. 224-232, 2003.

[72] K. S. McIver, A. S. Heath, and J. R. Scott, "Regulation of virulence by environmental signals in group A streptococci: influence of osmolarity, temperature, gas exchange, and iron limitation on emm transcription," Infection and Immunity, vol. 63, no. 11, pp. 4540-4542, 1995.

[73] M. G. Caparon, R. T. Geist, J. Perez-Casal, and J. R. Scott, "Environmental regulation of virulence in group A streptococci: transcription of the gene encoding $\mathrm{M}$ protein is stimulated by carbon dioxide," Journal of Bacteriology, vol. 174, no. 17, pp. 5693-5701, 1992.

[74] A. Podbielski, J. A. Peterson, and P. Cleary, "Surface proteinCAT reporter fusions demonstrate differential gene expression in the vir regulon of Streptococcus pyogenes," Molecular Microbiology, vol. 6, no. 16, pp. 2253-2265, 1992.

[75] J. C. Reitmeyer, R. K. Guthrie, and J. H. Steele, "The occurrence of nicotinamide adenine dinucleotide glycohydrolase and the serum opacity reaction in groups B, C, F and G streptococci," Microbios, vol. 58, no. 236-237, pp. 183-187, 1989.
[76] F. H. Top Jr. and L. W. Wannamaker, "The serum opacity reaction of Streptococcus pyogenes: frequency of production of streptococcal lipoproteinase by strains of different serological types and the relationship of M protein production," Journal of Hygiene, vol. 66, no. 1, pp. 49-58, 1968.

[77] D. R. Johnson, E. L. Kaplan, A. VanGheem, R. R. Facklam, and B. Beall, "Characterization of group A streptococci (Streptococcus pyogenes): correlation of M-protein and emmgene type with T-protein agglutination pattern and serum opacity factor," Journal of Medical Microbiology, vol. 55, no. 2, pp. 157-164, 2006.

[78] B. Luca-Harari, M. Straut, S. Cretoiu et al., "Molecular characterization of invasive and non-invasive Streptococcus pyogenes isolates from Romania," Journal of Medical Microbiology, vol. 57, no. 11, pp. 1354-1363, 2008.

[79] S. H. M. El Tayeb and E. M. M. Nasr, "Serum opacity factor of Staphylococcus epidermidis," Infection and Immunity, vol. 15, no. 1, pp. 335-336, 1977.

[80] V. Katerov, C. Schalen, and A. A. Totolian, "Sequencing of genes within the vir regulon of Streptococcus pyogenes type M15-an opacity factor positive serotype with low opacity factor expression," Molecular and General Genetics, vol. 245, no. 1, pp. 78-85, 1994.

[81] D. Takamatsu, K. Wongsawan, M. Osaki et al., "Streptococcus suis in humans, Thailand," Emerging Infectious Diseases, vol. 14, no. 1, pp. 181-183, 2008.

[82] J. B. Dale, T. Penfound, E. Y. Chiang, V. Long, S. T. Shulman, and B. Beall, "Multivalent group A streptococcal vaccine elicits bactericidal antibodies against variant M subtypes," Clinical and Diagnostic Laboratory Immunology, vol. 12, no. 7, pp. 833836, 2005.

[83] K. Schulze, E. Medina, S. R. Talay, R. J. Towers, G. S. Chhatwal, and C. A. Guzmán, "Characterization of the domain of fibronectin-binding protein I of Streptococcus pyogenes responsible for elicitation of a protective immune response," Infection and Immunity, vol. 69, no. 1, pp. 622-625, 2001.

[84] K. Schulze, E. Medina, and C. A. Guzmán, "Intranasal immunization with serum opacity factor (SOF) of Streptococcus pyogenes fails to protect mice against lethal mucosal challenge with a heterologous strain," Vaccine, vol. 24, no. 9, pp. 14461450, 2006.

[85] S. A. McNeil, S. A. Halperin, J. M. Langley et al., "Safety and immunogenicity of 26-valent group A streptococcus vaccine in healthy adult volunteers," Clinical Infectious Diseases, vol. 41, no. 8, pp. 1114-1122, 2005.

[86] L. Yvan-Charvet, N. Wang, and A. R. Tall, "Role of HDL, ABCA1, and ABCG1 transporters in cholesterol efflux and immune responses," Arteriosclerosis, Thrombosis, and Vascular Biology, vol. 30, no. 2, pp. 139-143, 2010.

[87] H. J. Pownall and C. Ehnholm, "The unique role of apolipoprotein A-I in HDL remodeling and metabolism," Current Opinion in Lipidology, vol. 17, no. 3, pp. 209-213, 2006.

[88] U. Tchoua, C. Rosales, B. K. Gillard, et al., "Streptococcal serum opacity factor enhances macrophage cholesterol efflux and plasma cholesterol esterification," submitted to The Journal of Biological Chemistry.

[89] N. Wang, D. L. Silver, P. Costet, and A. R. Tall, "Specific binding of ApoA-I, enhanced cholesterol efflux, and altered plasma membrane morphology in cells expressing ABC1," Journal of Biological Chemistry, vol. 275, no. 42, pp. 3305333058, 2000. 
[90] W. S. Davidson, C. Rosales, B. Gillard, et al., "Apolipoprotein A-I conformation in Streptococcal serum opacity factor-derived Neo HDL, a potent acceptor of macrophage cholesterol," in Proceedings of the Arteriosclerosis, Thrombosis and Vascular Biology Annual Conference, San Francisco, Calif, USA, 2010, abstract P89.

[91] C. Rosales, D. Tang, B. Gillard, H. S. Courtney, and H. J. Pownall, "Low dose Streptococcal serum opacity factor reduces plasma cholesterol in vivo," in Proceedings of the Arteriosclerosis, Thrombosis and Vascular Biology Annual Conference, San Francisco, Calif, USA, 2010, abstract P357.

[92] A. E. Frankel, B. L. Powell, N. S. Duesbery, G. F. Vande Woude, and S. H. Leppla, "Anthrax fusion protein therapy of cancer," Current Protein and Peptide Science, vol. 3, no. 4, pp. 399-407, 2002.

[93] M. de Maio, "Therapeutic uses of botulinum toxin: from facial palsy to autonomic disorders," Expert Opinion on Biological Therapy, vol. 8, no. 6, pp. 791-798, 2008.

[94] N. Sikri and A. Bardia, "A history of streptokinase use in acute myocardial infarction," Texas Heart Institute Journal, vol. 34, no. 3, pp. 318-327, 2007. 

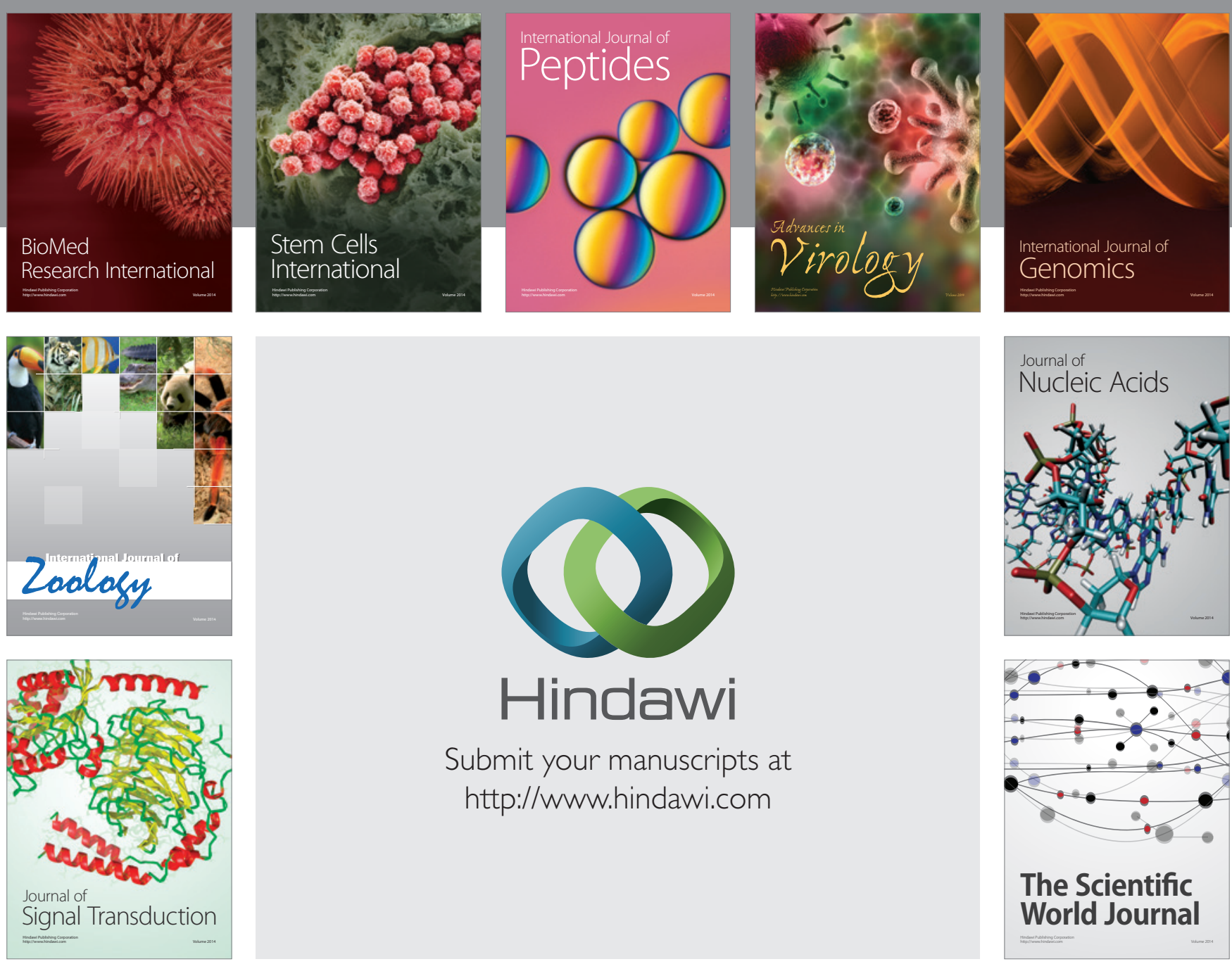

Submit your manuscripts at

http://www.hindawi.com
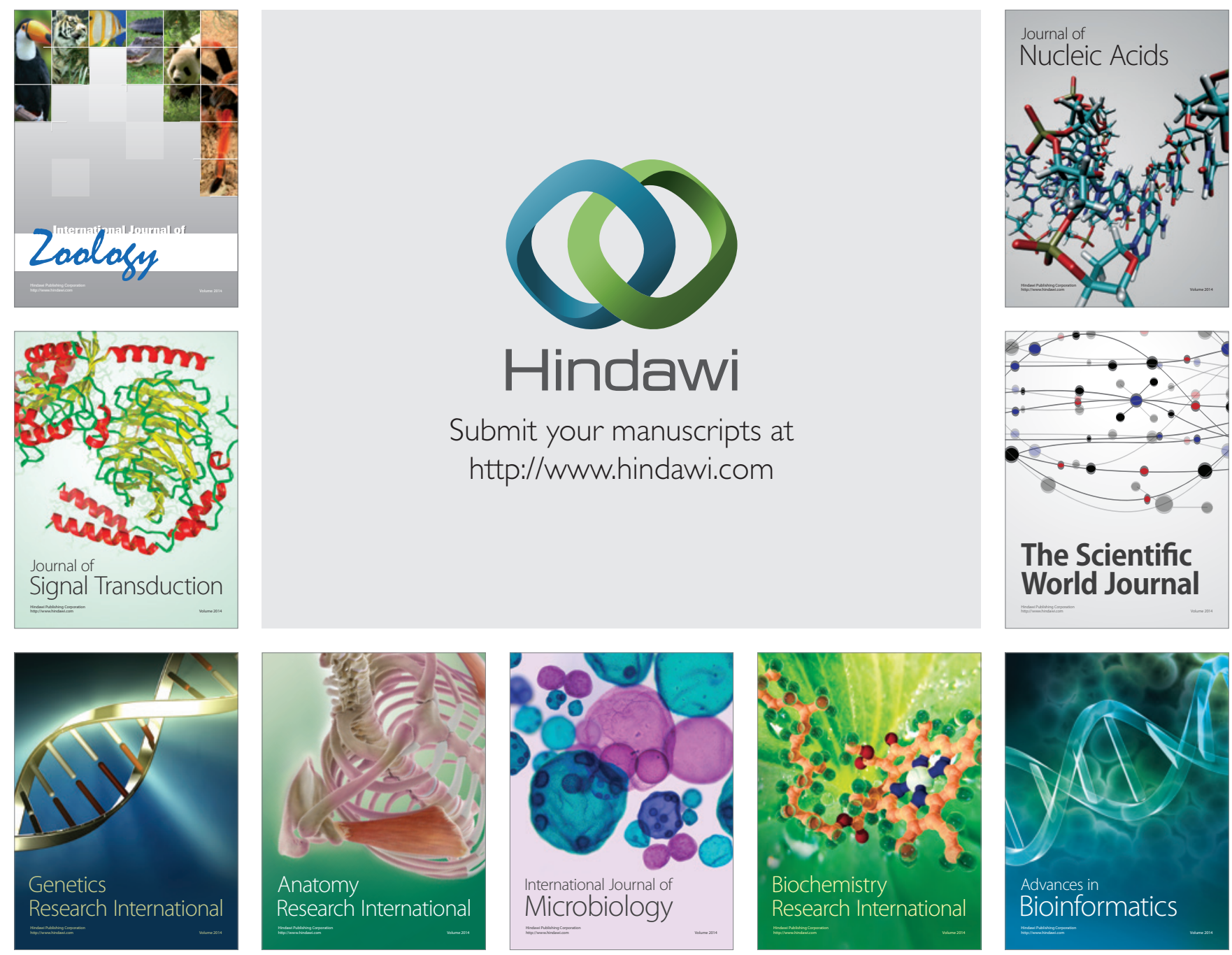

The Scientific World Journal
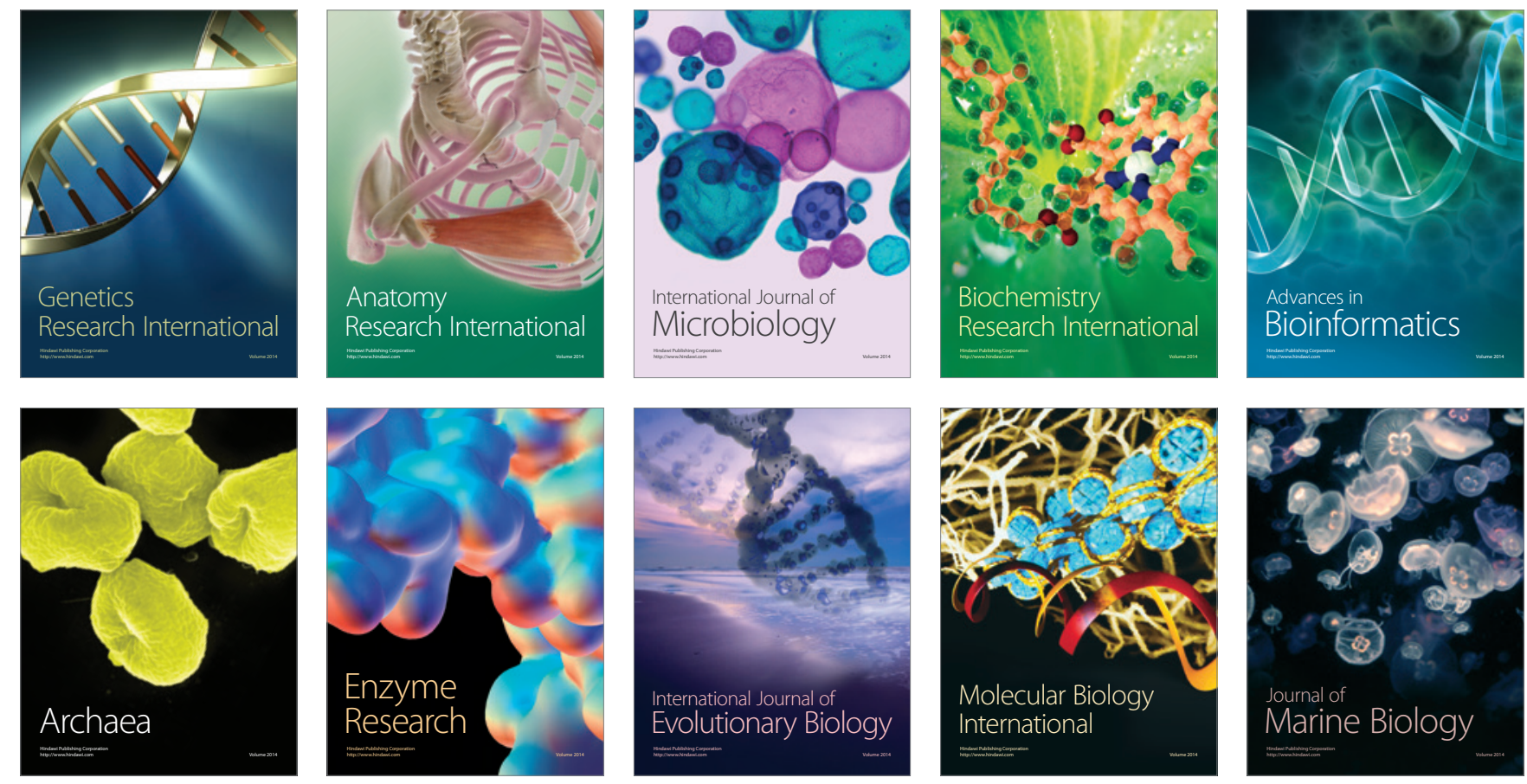